University of Louisville ThinkIR: The University of Louisville's Institutional Repository

Electronic Theses and Dissertations

$5-2019$

\title{
A multi-plot assessment of vegetation structure using a micro-unmanned aerial system (UAS) in a semi-arid savanna environment.
}

Nicholas E Kolarik

University of Louisville

Follow this and additional works at: https://ir.library.louisville.edu/etd

Part of the Natural Resources and Conservation Commons

\section{Recommended Citation}

Kolarik, Nicholas E, "A multi-plot assessment of vegetation structure using a micro-unmanned aerial system (UAS) in a semi-arid savanna environment." (2019). Electronic Theses and Dissertations. Paper 3216.

https://doi.org/10.18297/etd/3216

This Master's Thesis is brought to you for free and open access by ThinkIR: The University of Louisville's Institutional Repository. It has been accepted for inclusion in Electronic Theses and Dissertations by an authorized administrator of ThinkIR: The University of Louisville's Institutional Repository. This title appears here courtesy of the author, who has retained all other copyrights. For more information, please contact thinkir@louisville.edu. 


\title{
A MULTI-PLOT ASSESSMENT OF VEGETATION STRUCTURE USING A MICRO-UNMANNED AERIAL SYSTEM (UAS) IN A SEMI-ARID SAVANNA ENVIRONMENT
}

$$
\text { By }
$$

\author{
Nicholas E Kolarik
}

B.S. University of Louisville 2017

\author{
A Thesis \\ Submitted to the Faculty of the \\ College of Arts and Sciences of the University of Louisville \\ In Partial Fulfillment of the Requirements \\ For the Degree of
}

\begin{abstract}
Master of Science
Applied Geography
\end{abstract}

Department of Geography and Geosciences

University of Louisville

Louisville, KY

May 2019 



\title{
A MULTI-PLOT ASSESSMENT OF VEGETATION STRUCTURE USING A MICRO-UNMANNED AERIAL SYSTEM (UAS) IN A SEMI-ARID SAVANNA ENVIRONMENT
}

\author{
By \\ Nicholas E. Kolarik \\ B.S. University of Louisville 2017 \\ A Thesis Approved on \\ April 19, 2019
}

By the following Thesis Committee:

Andrea E. Gaughan, Ph.D.

Forrest R. Stevens, Ph.D.

Narcisa G. Pricope, Ph.D. 


\section{ACKNOWLEDGEMENTS}

I would like to thank Dr. Andrea Gaughan and Dr. Forrest Stevens for the guidance offered throughout this process. When I expressed interest in field work as a career goal, I was offered an opportunity to work in the field as part of a collaborative research effort and they shared their expertise. Both made themselves available to workshop methodological issues and academic decisions in the context of my work and larger goals. Through their mentorship, and that of the Geography Department as a whole, I have achieved well beyond what I initially intended as a student and am encouraged to carry the momentum forward. Dr. Carol Hanchette also deserves mention by name for inspiring me as a non-traditional undergraduate to pursue an advanced degree. Of course, no achievement would be possible without the dedicated partnership of Micki Scarborough and our loving dogs, providing more support than I probably deserve. 


\title{
ABSTRACT \\ A MULTI-PLOT ASSESSMENT OF VEGETATION STRUCTURE USING A MICRO-UNMANNED AERIAL SYSTEM (UAS) IN A SEMI-ARID SAVANNA ENVIRONMENT
}

\author{
Nicholas E. Kolarik
}

March 27, 2019

Unmanned Aerial Systems (UAS) have emerged as a capable platform for measuring vegetation health, structure and productivity. Products derived from UAS imagery typically have much finer spatial resolutions than traditional satellite or aircraft imagery, allowing the spectral and structural heterogeneity of vegetation to be mapped and monitored with more detail. This study uses UAS-captured imagery from the Chobe Enclave of northern Botswana. Flights were conducted across a gradient of savanna sites classified as grass-, shrub-, or tree-dominated. We compare multiple approaches for extracting woody vegetation structure from UAS imagery and assess correlations between in situ field measurements and UAS estimates. Sensor types were also compared, to determine whether multispectral data improves estimates of vegetation structure at the expense of spatial resolution. We found that leveraging multispectral reflectance information aids in crown delineation, areal estimates, and fractional cover of woody and non-woody vegetation within the study

area. Comparisons are made between two crown delineation techniques, and the efficacy of each technique within savanna environments is discussed. The methods presented hold potential to inform field sampling protocols and UAS-based techniques for autonomous crown delineation in future dryland systems research. These findings advance research for 
field and remote sensing analyses assessing degradation in heterogeneous landscapes where varying vegetation structure has implications on land use and land functions. 


\section{TABLE OF CONTENTS}

PAGE

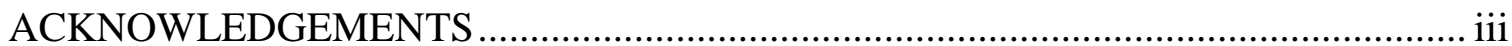

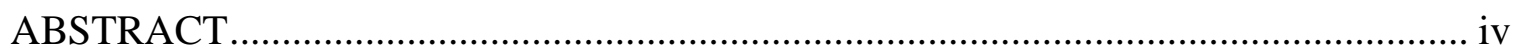

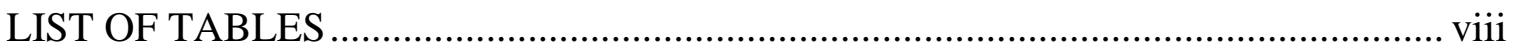

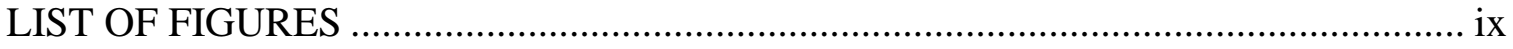

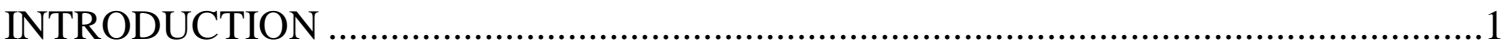

Unmanned Aerial Systems in Remote Sensing ....................................................

Photogrammetry: Structure from Motion with Multi-View Stereo ............................6

Existing Method for Individual Tree Crown Delineation .......................................

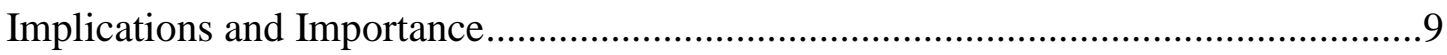

Research Objectives and Hypotheses .............................................................. 11

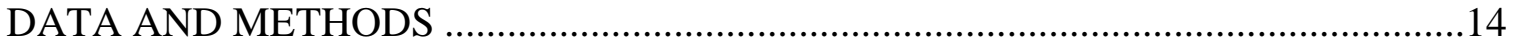

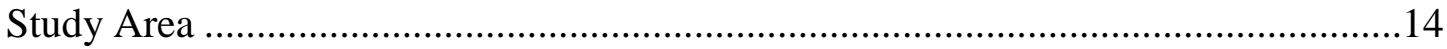

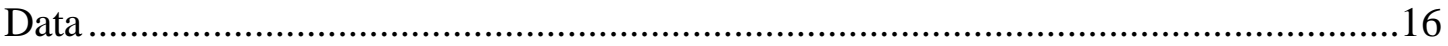

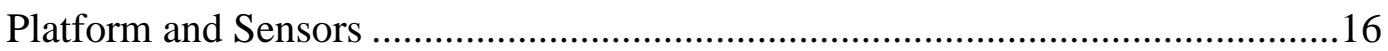

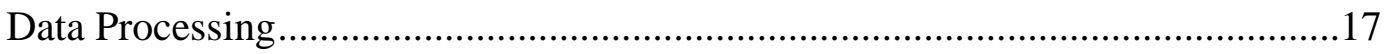

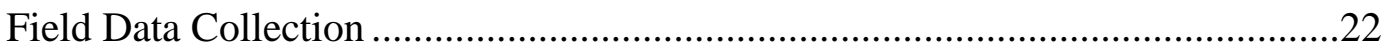

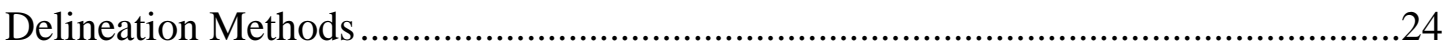

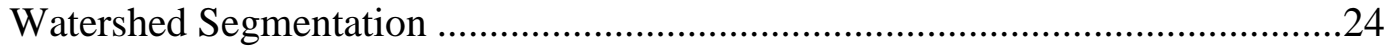

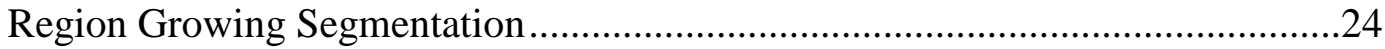

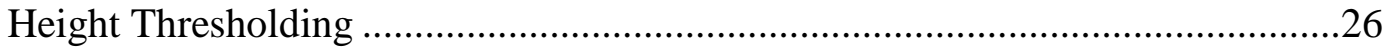

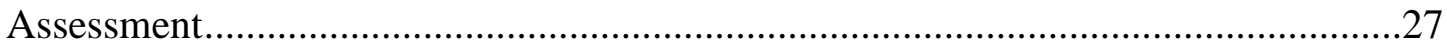




\section{TABLE OF CONTENTS (cont.)}

PAGE

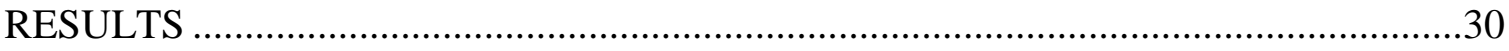

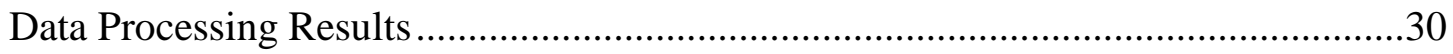

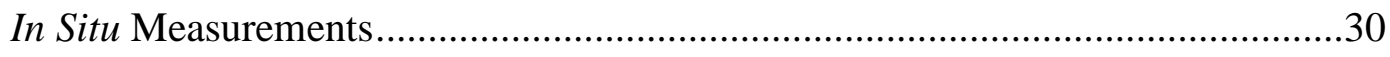

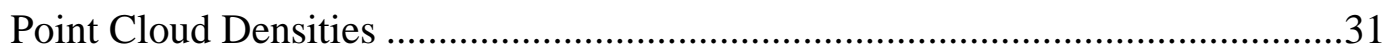

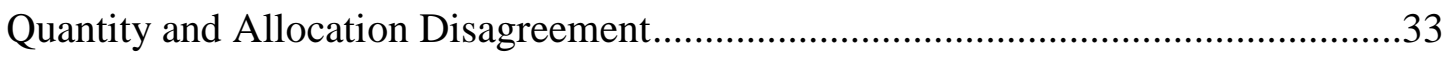

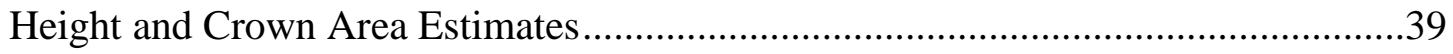

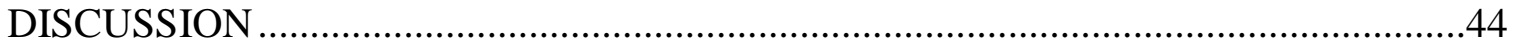

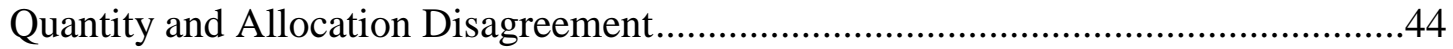

Crown Height and Area Comparisons .............................................................46

Limitations and Future Directions of Research ...............................................50

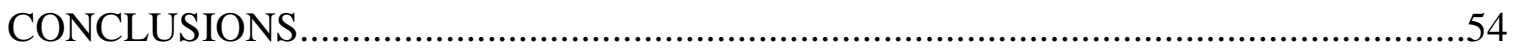

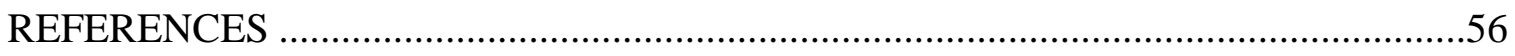

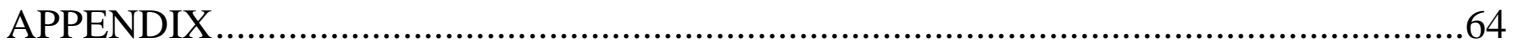

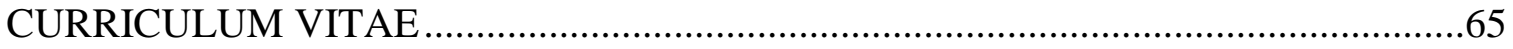




\section{LIST OF TABLES}

PAGE

Table 1. Total population of CECT villages in 2001 and 2011 censuses ..........................14

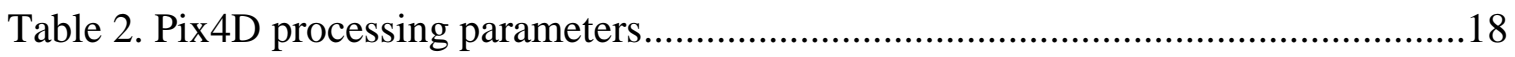

Table 3. Summary of in situ measurements ....................................................................31

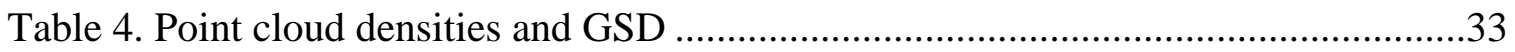

Table 5. Quantity, allocation, and overall disagreement ...................................................34

Table 6. Quantity, allocation, and overall disagreement among site types and methods ..35

Table 7. Confusion matrix and quantity and allocation metrics for boundary-based .........36

Table 8. Confusion matrix and quantity and allocation metrics for region growing .........36

Table 9. Confusion matrix and quantity and allocation metrics for height thresholding ..36

Table 10. Quantity, allocation, and overall disagreement for each band and class ............37

Table 11. Quantity, allocation, and overall disagreement for each band pooled................38 


\section{LIST OF FIGURES}

PAGE

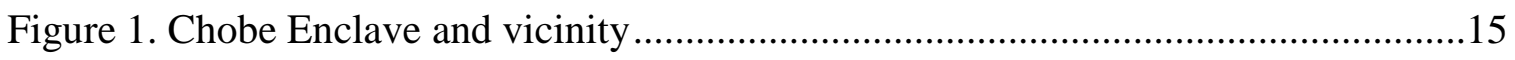

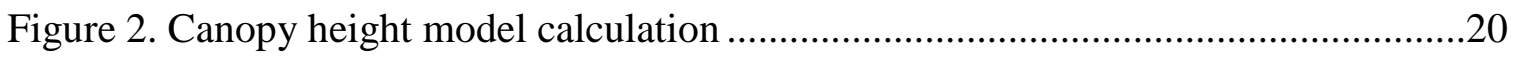

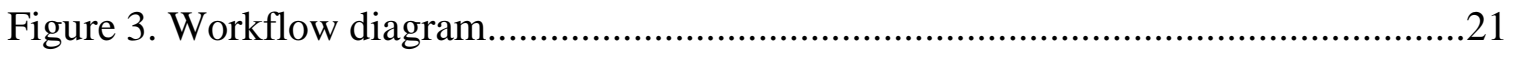

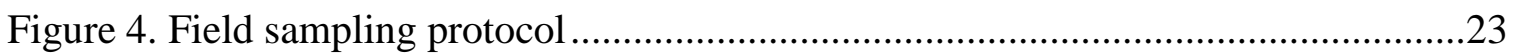

Figure 5. Results of region growing parameter testing ...........................................26

Figure 6. Algorithm output vector selection .......................................................29

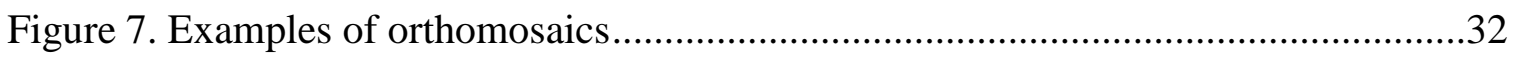

Figure 8. Vegetation cover classification.......................................................... 38

Figure 9. Comparison of height estimates ............................................................41

Figure 10. Comparison of crown area estimates....................................................42

Figure 11. Visual comparisons of segmentation algorithms......................................43 


\section{INTRODUCTION}

A thorough understanding of land functions is integral in the development of mutually beneficial relationships among human and non-human systems. Provisions of goods and services by the land system (Verburg et al. 2009), land functions not only provide insight to current measurable results of land cover change, but the trajectory of land cover dynamics as well. As models in land change science become increasingly more complex, remote sensing of the environment remains a fundamental necessity in efforts towards understanding the roles of various species and surficial features present (Verberg et al. 2004; Olson et al. 2008).

Savannas represent an important type of dryland system, covering one fifth of the Earth's land mass and supporting large wildlife and human populations (Herrerro, Southworth, and Bunting 2016). In the Kavango-Zambezi Trans-frontier Conservation Area (KAZA) of Southern Africa, altered precipitation regimes and increases in population of humans, livestock, and wildlife can potentially affect land function, and may exhibit positive feedbacks leading to degradation of the landscape (Van Langevelde et al. 2002, Ward 2005). These among other processes contribute to a phenomenon known as "bush encroachment", a pattern of degradation in semi-arid environments that interrupts the non-equilibrium nature of savannas towards a steady-state of shrub domination (Roques, O’Connor, and Watkinson 2001, Van Auken 2009). Though not always linked to functional degradation (Eldridge et al. 2011), a shift towards a shrub-dominated equilibrium has potential implications tied to how the land functions in the various systems present in terms of biodiversity and resource availability (Roques, O’Connor, and Watkinson 2001, Van Auken 2009). 
Satellite data are widely accepted and have long been used in remote sensing analyses to provide objective landscape level vegetation estimates relating to productivity, biomass, and extent of cover. Where early work relied on field measurements, satellite remote sensing platforms allow for analysis of systematic repeat measurements over large swaths of land with regards to vegetation phenology and productivity, albeit at a much larger spatial grain (Avery and Burkhartn 2001; Zhang et al. 2003; Feng et al. 2007). Beyond these abilities, however, satellite data driven analyses tend to fall short when structural characteristics are of interest, as spatial resolutions of these data traditionally are inherently coarse and contain pixels with mixed cover (Hermann and Tappan 2013). What is more, coincidental seasonal greening cycles have been found to complicate the differentiation between herbaceous and woody covers (Apko 1997). Ecological differences in woody species establishment can be difficult to resolve, but important when assessing functional properties of vegetation cover (Brown, Valone, and Curtin 1997).

Difficulties and inconsistencies associated with using imagery collected via satellite also include atmospheric effects, cloud cover, temporal restraints, and seasonality. These can be minimized through the collection of data with Unmanned Aerial Systems (UAS) with flexible timing, in desirable conditions, and at low altitudes (Zhang and Kovacs 2012). Furthermore, low altitude flights produce centimetric ground sampling distances that are much finer than data collected via satellite platforms. Flight parameters in the field, controlled by the researcher, enable data collection tailored to the needs of specific projects, delivering fine-scale imagery unobfuscated by limitations typical of data collected by sensors aboard traditional satellite or platforms (Anderson and Gaston 2013). 
Three-dimensional structural information on the environment derived from remote sensing platforms has shifted scientific understanding of landscape phenomena and conditions. UAS surveys provide a substitute for early methods of ecosystem structure data collection that are both time consuming and labor intensive (Avery and Burkhartn 2001, Zahawi et al. 2015). This more logistically flexible method collects fine-resolution imagery at low-cost via UAS and has been shown to be effective for quantifying vegetation structure as well as estimating fractional vegetation coverage (Cunliffe, Brazier and Anderson 2016; Mayr et al. 2017). Despite these advances, a gap remains in the understanding of the utility of the spectral range of sensor payloads can be extended into the near infrared (700 $\mathrm{nm}$ to 900 $\mathrm{nm})$. Combined with the spatial grain and temporal fidelity of UAS data, increased spectral detail could further enable the ability to extract structural information for a given landscape. Reflectance measured in the near-infrared (NIR) portion of the electromagnetic spectrum is widely known to be useful for estimating the health and coverage of productive vegetation (Tucker 1979; Curran 1980). NIR reflectance values are shown to be highly sensitive to plants with active chlorophyll, which are excellent reflectors of energy at wavelengths between $700 \mathrm{~nm}$ and $900 \mathrm{~nm}$ (Jensen 2016). NIR reflectance is also regularly used for ratio-based proxies of greenness and vegetation health such as the normalized difference vegetation index (NDVI), but the red edge $(680-750 \mathrm{~nm})$ has also been shown to be very descriptive of active chlorophyll content in remote sensing analyses though utilized less often (Filella and Penuelas 1994). While this transition from the red to NIR is sensitive to changes in phenology and productivity across space and time, there have been mixed results with the comparison of red edge and NIR reflectance in some applications (Adelabu, Mutanga and Adam 2014; Kross et al. 2014). The differences between these portions of the 
spectrum prove be useful for distinguishing within-flight differences in vegetation characteristics but also complicate standardization and comparison between flights. Regardless of these difficulties, reflectance in the red edge and NIR are known to be variable between species and seasons and could prove very useful for extraction of structural information in a highly heterogeneous landscape in terms of species and structure.

While ground observations are frequently relied upon to provide estimates of vegetation and other land cover used for validation of satellite data (Foody 2015), these are often constrained measures that could possibly be improved through a consistent, systematic workflow that incorporates unmanned aerial systems (UAS) and high spatial resolution data. UAS have potential to mitigate the challenges of linking ground-based observations typically used to validate satellite data and the contrast in resolution can thus be quantified and scaled in a systematic manner that does not rely on human estimates (Marx, McFarlane, and Alzahrani 2017). Structural information derived from UAS imagery can also provide grounds upon which to estimate relative value of vegetation present in terms of structure for in systems of interest. Although it is not uncommon for studies to utilize data from UAS platforms in this manner (Dandois and Ellis 2010; Mayr et al. 2017), incorporation of data in the NIR is less explored.

At spatial resolutions typically collected via satellite remote sensing platforms, vegetation community structure is very difficult to resolve (Lambin 1999). This challenge impedes analysis of land cover modification, where more subtle changes occur on a given landscape. Though more common than land conversions, these changes are not captured by typical land cover classification at relatively coarse resolutions characteristic or traditional 
remote sensing analysis and are prone to misinterpretation (Lambin 1999; Herrmann and Tappan 2013).

Savanna communities are typified by a gradation of various states of woody cover. Tree, shrub, and grass covers are determined by many factors that dictate various disturbance regimes such as fire and herbivory (Van Langevelde et al. 2002), precipitation inputs (Gaughan et al. 2011; Gibbes et. al 2014; Pricope et al., 2015) as well as soil properties and nutrient availability dictated by interactions between and among vegetation types (Scholes and Archer 1997; Roques, O’Connor, and Watkinson 2001). It is the interplay of these four determinants: fire, herbivory, soil properties, and water availability that dictate vegetation structure in semi-arid savannas globally (Scholes and Archer 1997). Distinguishing between various savanna states using two-dimensional satellite imagery is difficult and the potential for integrating UAS methods for quantifying extents of varying stages of woody cover is intriguing and should be thoroughly explored.

\section{Unmanned Aerial Systems in Remote Sensing}

Aerial photographs historically have been collected from various platforms including kites and balloons prior to the integration use of manned aircrafts, which provided distinct advantages in terms of maneuverability and weather dependence (Eisenbeiß 2009). However, while potentially valuable for analysis of surficial features, these data are expensive to collect through methods that require a piloted vehicle.

UAS are now frequently employed in a wide variety of operations and are capable of performing many tasks with no risk to the pilot. Described by Colomina and Molina (2013), the largest UAS are typically reserved for tactical military applications, using complex 
avionics and operate at high altitudes and endurance. A step below tactical drones, these authors categorize vehicles from $150 \mathrm{~kg}$ to $1250 \mathrm{~kg}$ as "close-short-medium-range UAS" typically used in the private sector for various remote sensing applications and operating at a range between $10 \mathrm{~km}$ and $70 \mathrm{~km}$. These larger platforms are discussed in detail in a comprehensive review of UAS by Eisenbeiß (2009). For the sake of brevity, and applicability to the goals of this research, mini- and micro-UAS are the systems of interest, as off the shelf systems will occupy this space. These mini and micro-UAS are typified by lower endurance and range and are restricted to lower airspaces than those aforementioned. Defined by the Federal Aviation Administration (FAA) as unmanned vehicles less than 55 pounds and greater than 0.5 pounds, many of these vehicles are available for service off the shelf, and often employed by both hobbyists and researchers. Miniaturization of global positioning systems (GPS), inertial measurement units (IMU), and general avionics make micro-UAS highly accessible and reasonable tools for collecting aerial imagery for scientific analysis (Colomina and Molina 2013).

\section{Photogrammetry: Structure from Motion with Multi-View Stereo}

Photogrammetric techniques allow for the derivation of three-dimensional estimates from sets of overlapping two dimensional photos. Advances in computational efficiency in recent years enable for efficient and realistic representations of surficial features through the production of three-dimensional point clouds analogous to the output of Light Detection And Ranging (LiDAR) surveys, which represent the current standard in three-dimensional surface estimation (Smith, Carrivick, and Quincey 2013). This process of establishing keypoints in multiple overlapping photos to produce a sparse point cloud (Structure from Motion (SfM)) 
and subsequently densifying the point cloud (Multi-View Stereo (MVS)) has been applied in many fields and provides safe, relatively inexpensive opportunities for extraction of detailed surface and structural information.

As a result of the combined field and software processing appeal, applications for off the shelf systems combined with low to moderately priced sensors have provided fineresolution datasets used for studies in geomorphology (Tonkin et al. 2014; d'Oleire-Oltmann et al. 2012), archaeology (Georgopoulos et al. 2016), ecology (McDowall and Lynch 2017), forestry (Torresan et al. 2017), precision agriculture (Mathews and Jensen 2013; Chen et al. 2017), and infrastructure maintenance (Hollerman and Morgenthal 2013) among others. In each of these studies, point clouds produced using photogrammetric workflows provide three-dimensional information at a fraction of the cost of a LiDAR survey and have been shown to be comparable to those produced via LiDAR (Jensen and Mathews 2016; Dandois and Ellis 2010). While some attention has been given to integrating multispectral data into LiDAR analyses to improve individual tree crown delineation (Zhen, Quackenbush, and Zhang 2016; Lindberg and Holmgren 2017), SfM-MVS point cloud generation is typically performed on images captured in the visible portion of the spectrum only. However, affordable multispectral sensors such as Micasense products (RedEdge and Parrot Sequoia) open the door for the integration of data collected into the NIR portion of the electromagnetic (EM) spectrum into low-cost micro-UAS studies.

\section{Existing Methods for Individual Tree Crown Delineation}

Aerial photography has been used for individual tree crown delineation (ITCD) since the mid-20th century, but automated techniques did not begin to emerge until the mid-1980's 
(Zhen, Quackenbush, and Zhang 2016). Until an archive of high-resolution satellite products was established through platforms such as QuickBird, WorldView, and IKONOS, the only imagery useful for the task of ITCD was aerial imagery due to its inherent advantage in ground sampling distance (GSD) (Ke and Quackenbush 2011). Aerial platforms are used extensively in early ITCD research efforts (Gougeon 1995), some including multispectral sensors such as the Multi-detector Electro-optical Imaging Sensor (MEIS-II) (Gougeon and Moore 1988) and even hyperspectral data from the Compact Airborne Spectrographic Imager (CASI) (Anger, Mah, and Babey 1994).

Methods for ITCD using passive input data such as these require image segmentation techniques that are classified as either boundary-based or region growing image segmentations (Carleer, Debeir, and Wolff 2005). While both focus on differentiation between objects of interest (tree crowns) and the background, the algorithms are inherently different based upon the approach. In short, boundary-based algorithms are predicated on delineating objects using dissimilarity properties, where region-growing techniques begin with seeds and iteratively group neighboring pixels based on similarities between them (Zhang 1997).

Recent efforts in ITCD, however, focus on data collected by active sensors such as LiDAR due to the highly detailed individual tree information provided by multiple returns from emitted light (Ke and Quackenbush 2011). Zhen, Quackenbush, and Zhang (2016) report with a thorough review of ITCD research from 1990 to 2015 that $52.9 \%$ of the related literature within this time period focuses on active sensors, with another $11.0 \%$ using combined active and passive data. This proliferation within the discipline demonstrates the acceptance of active sensors and resultant point clouds as the benchmark for structural 
vegetation information, however these data are often cost-prohibitive and not always practical to implement (Ke and Quackenbush 2011).

Due to the inherent cost of LiDAR data, point clouds produced using photogrammetric techniques have been explored as cost-effective alternatives and concomitant products have been compared directly to those from LiDAR sensors. Wallace et al. (2016) demonstrate that comparable estimates of upper canopy are produced using both SfM and LiDAR point clouds, however SfM falls short when trying to resolve sub-canopy conditions. LiDAR pulses are able to penetrate the upper canopy and return information about the understory that is occluded in aerial photos used for photogrammetric techniques. This drawback aside, SfM-MVS point clouds produced in this 2016 study show the ability to provide useful and reliable structural information at more reasonable cost than LiDAR.

\section{Implications and Importance}

Quantifying vegetation structure in the context of KAZA is important for understanding land function in human and non-human systems. The gradation of trees, shrubs, and grasses in savanna environments is a prime example of a dynamic ecosystem highly dependent on four determining factors: herbivory, precipitation, soil properties, and fire (Scholes and Archer 1997). Land use and management in recent years have shown to strongly influence the vegetation trajectory, particularly fire and grazing disturbance regimes which are often closely related to the positive feedback phenomenon known as bush or shrub encroachment (Roques et al. 2001). For instance, overgrazing may reduce perennial grasses, decreasing fuel loads that would typically increase fire intensity and regulate woody growth (Van Langevelde et al. 2002). Subsequently, newly established shrubs and trees have a 
competitive advantage over grasses in access to available water due to broad root systems (Eldridge et al. 2011) and also provide nutrients to themselves via leaf litter in self-catalytic manner fostering further woody growth (Scholes and Archer 1997). Increased carbon dioxide in the atmosphere is also beneficial to woody vegetation that sequesters carbon and more efficiently than herbaceous counterparts when $\mathrm{CO}_{2}$ levels are high (Ward 2005).

VanLangevelde et al. (2002) explain that this phenomenon is intrinsic to the positivefeedback mechanisms of grazing and fire in that increases in grazing pressure provide less fuel for fires that would prevent woody recruitment. Ward (2005) argues that precipitation and increased $\mathrm{CO}_{2}$ in the atmosphere are the main drivers of woody establishment and persistence. Alternatively, Stevens et al. (2016) recognize the role of local extinctions of megafauna keystone species such as the African elephant (Loxodonta africana) in the establishment of woody vegetation that would be prime fodder. Brown, Valone, and Curtin (1997) argue that a climatic shift is responsible for shrub encroachment in the American southwest, where grazing and fire pressures are far less influential. While specific causes and interactions may differ between savanna sites, altered determinants are leading to observed differences in woody cover in savannas across the globe.

The savanna state in any particular zone determines how the land will function ecologically as well as what resources are available for human use. Organisms that rely on grasses and trees have been extirpated when land shifts to a shrub encroached state (Brown, Valone, and Curtin 1997). Similarly, shrub dominated savanna cannot be utilized for grazing, are difficult to cultivate, and do not provide significant amounts of timber, fuelwood, or polewood needed by established human populations. In both systems, an increase in shrub cover can decreases biodiversity devaluing the land in an ecological sense as well as in terms 
of resource availability for human use (Roques, O'Connor, and Watkinson 2001, Van Auken 2009).

Effectively quantifying vegetation structure at the scale provided by the UAS holds potential to extend measurements to products with greater spatial and temporal extents. It would be reasonable to then analyze these measurements in the context of varying institutions, management tools, and policies across KAZA. This effort could help to elucidate the practices that minimize degradation and quantify their bounds. Conservation efforts globally struggle to minimize biodiversity loss while maintaining or improving upon livelihoods of those that live closest to protected areas (DeFries et al. 2007). The greater crux of balancing conservation and development is too great for this thesis; however, the first step in a multi-scalar remote sensing effort can be explored by assessing correlations of in situ measurements of woody vegetation with estimates made from UAS derived SfM-MVS point clouds across the vegetation gradient that defines savanna environments.

\section{Research Objectives and Hypotheses}

1. Analyze woody vegetation estimates derived from point clouds produced using SfMMVS in tree-, shrub-, and grass-dominated savanna sites. Hypothesis 1: Estimates of woody cover are simplest in grass dominated sites and sites with grassy understory.

2. Compare point clouds produced using imagery captured in discrete spectral bands into the NIR portion of the spectrum with those produced using RGB imagery for delineation of woody individuals in various savanna environments. Hypothesis 2: Spectral bands into the NIR portion of the spectrum (730 $\mathrm{nm}$ to $810 \mathrm{~nm}$ ) will provide 
better estimates of vegetation structure than RGB point clouds despite a trade-off in spatial resolution.

3. Evaluate various methods used in LiDAR studies for individual tree crown delineation using SfM-MVS point clouds with respect to height and crown area estimates against in situ measurements. Hypothesis 3: Region growing segmentation will more closely resemble in situ measurements and canopy cover than a boundarybased segmentation technique.

This study asks these questions stratified across sites representative of savanna with different classes of dominant vegetation in order to determine how structural composition affects estimation of vegetation characteristics using SfM-MVS. It also addresses whether data captured from the NIR portion of the electromagnetic spectrum might improve estimates of height and crown area. These are derived from SfM-MVS point clouds from data collected within tree-, shrub-, and grass-dominated savannas. These questions directly relate to ways in which vegetation structure affects and informs land function, as degradation in the savanna context can be related directly to structure rather than productivity in many contexts (Roques, O'Connor, and Watkinson 2001; Van Langevelde et al. 2002; Pricope et al. 2015). Through establishing the efficacy of derived UAS datasets for describing structural characteristics of a region of interest, estimates provided through the workflow to follow can be considered more consistent and systematic than traditional reference sample collection. Potentially, this method could both corroborate other more subjective measures relied upon in the field as 
well as leverage NIR information to discern structural classes and inform remote sensing analyses at greater temporal and spatial scales. 


\section{DATA AND METHODS}

\section{Study Area}

Flights were conducted in a northern Botswana area known as the Chobe Enclave (Figure 1). Within Chobe Enclave, five village centers Kachikau, Kavimba, Mabele, Parakarungu, and Satau comprise what is known as the Chobe Enclave Community Trust (CECT); a community based organization heavily reliant on tourism activities. Villages in CECT experienced varying levels of population growth between the 2001 and 2011 censuses, with an overall growth of $13.66 \%$ (Table 1; Botswana 2011). Communal lands within CECT are utilized for grazing cattle and subsistence agriculture (Pricope et al. 2015), but due to poor soils and generally arid climate, agricultural yields are low. A 2015 study found, howeverm that cattle to outnumber humans by more than two to one in CECT (Stone 2015).

\begin{tabular}{cccc} 
Village & $\mathbf{2 0 0 1}$ & $\mathbf{2 0 1 1}$ & \% Change \\
\hline Kachikau & 881 & 1356 & 53.92 \\
Kavimba & 519 & 549 & 5.78 \\
Mabele & 696 & 773 & 11.06 \\
Parakarungu & 806 & 845 & 4.84 \\
Satau & 730 & 605 & -17.12 \\
\hline Total & $\mathbf{3 , 6 3 2}$ & $\mathbf{4 , 1 2 8}$ & $\mathbf{1 3 . 6 6}$
\end{tabular}

Table 1. Total population of CECT villages in 2001 and 2011 censuses (Botswana 2011).

To the north, the Chobe River and its floodplain separate five main village centers from Namibia, while to the south lies the Chobe Forest reserve. Beyond the forest lies Chobe National Park (CNP) the second largest park in southern Africa $(10,566 \mathrm{~km} 2)$ and widely 
known for its wealth of wildlife. Vegetation tends to differ dependent upon elevation, with a gradation of woodlands and scrub found in higher elevations while alluvial soils within the floodplain are characterized by grassier terrain. Typical of savanna environments, heterogeneous vegetation cover is common, with multiple species present in various stages of succession as determined by various disturbances. Precipitation in CECT is typically limited to $650 \mathrm{~mm} /$ year and is seasonally variable due to the shifting ITCZ, with wet season occurring from October to April (Nelleman, Moe, and Rutina 2002).

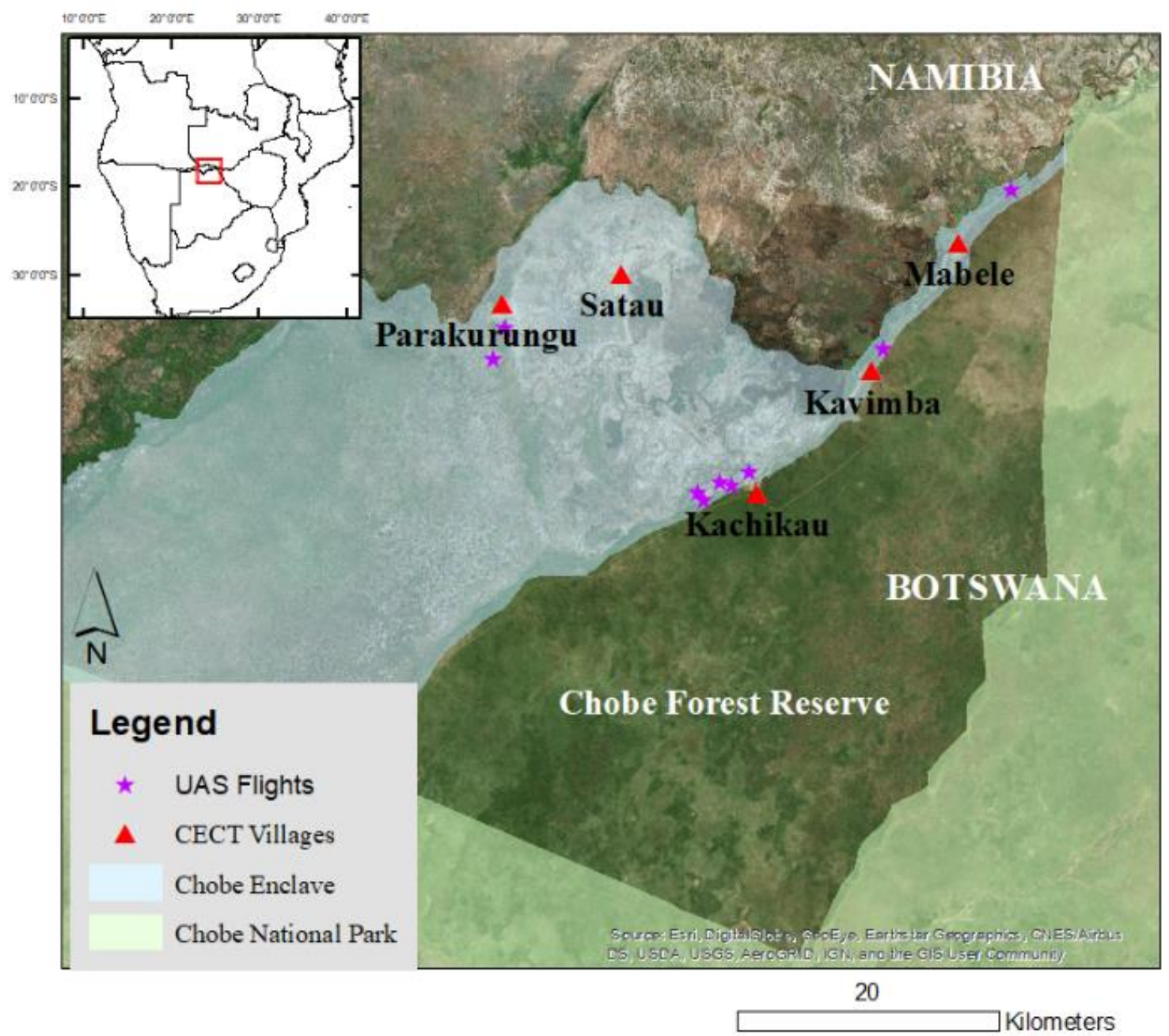

Figure 1. Chobe Enclave and vicinity. UAS flights, $n=9$ 
Data

Platform and sensors

A micro-quadcopter, the DJI Mavic Pro, was chosen for this study and outfitted with two sensors. Attached as a stock feature to the Mavic quadcopter is a three-axis, gimbalstabilized 12-megapixel RGB camera (DJI, Shenzhen, China), and below the Parrot Sequoia multispectral sensor was mounted with the corresponding sunlight irradiance sensor mounted above (Micasense, Seattle, WA, USA). At only 135 grams for the sunshine sensor, camera, and cable, the four band multispectral sensor collects narrowband imagery in green, (530-570 $\mathrm{nm})$, red (630-670 nm), red-edge (730-740 nm), and near-infrared (NIR) (770-810 nm) portions of the EM spectrum while well within the payload capacity of the DJI Mavic Pro. Red-edge and NIR sensors are ideal for vegetation measurements, due to the properties of active chlorophyll that make healthy leaf structures excellent reflectors of energy in this portion of the spectrum (Jensen 2016). Flown leveraging autonomous capabilities of the DJI Mavic Pro, 200 x 200 meter double-grid patterns at 100 meter altitude were navigated with the on-board GPS and IMU via the Pix4Dcapture application on a smart device. Photos were captured to ensure $85 \%$ frontal overlap and $70 \%$ side overlap at minimum, sampling the study area according to recommendations for UAS image acquisition in the SfM-MVS workflow (Pix4D 2017). Flights were conducted at midday to minimize shadow effects. Though flight times did vary slightly, the use of the sunlight irradiance sensor mounted above the aircraft acts to normalize differences in light and reflectance between flights (Pix4D 2017). 


\section{Data Processing}

Several photogrammetric software options exist to employ the SfM-MVS approach all generating comparable output products suitable for geographic analyses (Colomina and Molina 2014). For this research, the Pix4Dmapper version 3.4.31 software package was chosen to process images collected from both sensors (Pix4D, Lausanne, Switzerland). Sensor consideration and ease of operation were influential in this decision, as the Pix4Dmapper is a package designed in collaboration with Micasense, developers of the Parrot Sequoia. Furthermore, the software is well documented and provides a graphical user interface that is not as technically demanding as many of the open-source options. In choosing Pix4D, we also benefit from the technical support network associated with proprietary software. While open source options exist and generate comparable products, the support and capabilities specific to Pix4Dmapper helped guide our decision.

Optimal processing parameter values were given great consideration before final values were set. Through testing of isolated parameters, deviations from the default settings were determined to improve the quality of the output products. Parameters were optimized with an emphasis on producing the most accurate output products at the highest visual quality despite computational intensity (Table 2). After experimentation, these were the parameter settings we found to generate point clouds and resulting products most useful to our analysis. 


Parameter
Alternative
calibration
Full
image
scale

Window matching
size- 9x9
Triangulation
raster interpolation

Optimized for aerial nadir images with accurate geolocation.

The original image size is used when computing additional 3D points. More points computed than with half image scale, especially in areas where features can be easily matched.

The larger window improves accuracy for densified points in original images. Suggested for terrestrial images.

Based on Delauney triangulation, output rasters are more detailed than inverse distance weighting products.
Requirements/ Considerations

Requires $75 \%$ of images to contain spatial information.

Computationally intense- may require four times more RAM than half image scale (default).

Slower processing

Noise potential due to less smoothing

Table 2. Pix4D processing parameters differing from default values. Parameters were adjusted to maximize quality and effectively capture as much structural detail regardless of computational cost.

Images captured with each sensor of the Parrot Sequoia were sorted by band to ensure that output products were independent of all other bands of spectral data. Resulting in high fidelity point clouds generated for each band of Sequoia data and a point cloud for the Mavic RGB data, outputs could be tested against in situ measurements to determine if additional multispectral information is useful in measuring vegetation structure in various ways throughout the study area. Geolocation of each point cloud was performed within the SfM workflow utilizing location information of captured photos. Location data stored in EXIF tags collected via on-board navigation system of the Mavic as well as the internal GPS within the Parrot Sequoia (and illumination sensor), allow for point cloud placement in threedimensional space without the use of ground control (Turner, Lucieer, and Wallace 2014). This method, while known to be inferior to methods incorporating intensive ground control survey, provides reasonable location accuracy in a small fraction of the time required for an intensive ground control survey (Padró et al. 2019). 
At the time of capture, radiometric reflectance images were collected with the intention of performing radiometric calibration. However, many of the calibration images collected in the green band were considered by the software to be "overexposed", disabling this feature. As directed by contact with Pix4D engineers, relative within flight surface reflectance was the best option if trying to incorporate all bands into analysis. As was the case, this study relies only on the illumination sensor to normalize within flight reflectance observed on the surface.

Two-dimensional output products generated from point clouds as a result of Pix4D processing include a digital surface model (DSM), digital terrain model (DTM), orthomosaics and reflectance maps for RGB images and each individual Sequoia sensor respectively. Mavic RGB imagery resulted in 2D products with a mean of $3.46 \mathrm{~cm}$ ground sampling distance (GSD), and Sequoia products a mean of $10.41 \mathrm{~cm}$ GSD. DTMs, due to the nature in which they are estimated, are generated with a pixel size of five times the GSD by default. Derived from these were products to further inform our knowledge of the vegetation structure and nuance, such as a canopy height model calculated simply by subtracting the DTM from the DSM (Figure 2) (Levick and Rogers 2008). The Pix4D environment also generates a normalized difference vegetation index (NDVI) map from reflectance map values, though not utilized in this study. 

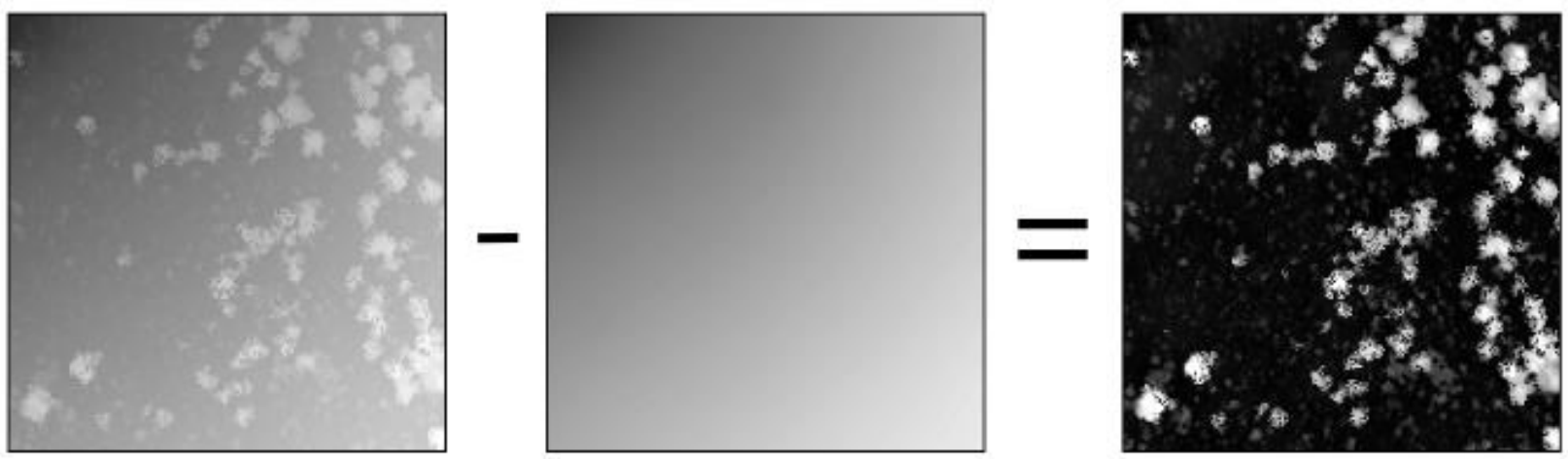

Figure 2. Canopy Height Model (CHM) calculation. DSM - DTM = CHM

Products generated for each sensor were then identically subsetted with a tool-chain developed using ArcGIS tools through the Python 2.7 environment (ESRI, Redlands, CA). Guided by the GSD calculator provided by Pix4D, we determined a buffer of 45 meters in every direction from each image geotag would provide suitable image overlap and undistorted estimations of reflectance and spatial information (Pix4D 2017). Leveraging the geotags stored in EXIF data for each image, a point was created for each photo and was buffered to 31.8 meters. A quadrilateral boundary was then drawn surrounding the buffered areas which was then used to subset each dataset. This conservative buffer accounts for instances where measurements from points to the bounded box are not perpendicular and could possibly exhibit distortion due to insufficient overlap. All Sequoia CHM were coregistered (georectified) to Mavic RGB data to compensate for minor differences in geolocation due to global navigation satellite system (GNSS) hardware differences in the absence of ground control (Figure 3). 


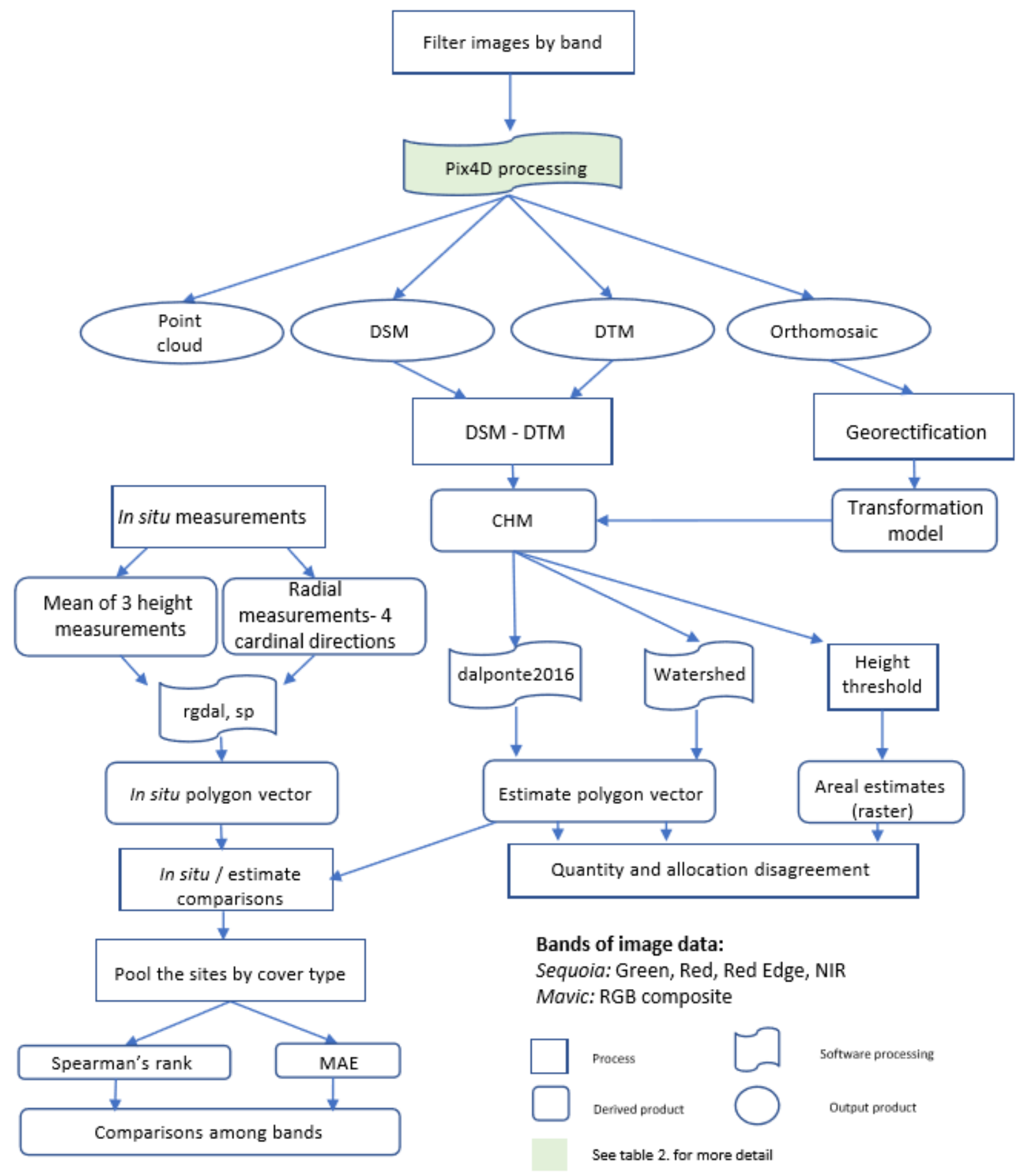

Figure 3. Workflow diagram. Images for each band of the Parrot Sequoia multispectral sensor are processed individually for comparison against the RGB data as a baseline. A transformation model for each dataset was applied to each CHM derived from SfM-MVS processing. Delineation methods are then applied to each CHM, enabling assessment of methods, site types, and input data. 


\section{Field data collection}

Sites were opportunistically sampled and stratified to ensure each category of savanna cover, grass-, shrub-, and tree-dominated sites were equally represented. Three sites within each category were identified to serve as reference samples to conduct a more intensive analysis of vegetation structure. Following a modified Center for the study of Institutions, Population, and Environmental Change (CIPEC) protocol for collection of reference sample information with regards to vegetation cover, areas were chosen that represent $90 \times 90$ meter areas with homogeneous vegetation cover. Typically, the field analyst would collect a point sample using a GNSS device and provide estimates of ground and vegetation cover. These point estimates are then used to later classify the pixels within this area, useful for areas such as those in the Chobe Enclave with heterogeneous ground and vegetation cover. It is emphasized that these estimates are not a replacement for rigorous ecological sampling (Randolph et al. 2005), but are meant to serve as means to describe vegetation structure and ground cover that have implications in human and non-human systems.

Since we aim to use UAS estimates to provide a more objective measure of vegetation cover, a sampling scheme was devised to randomize the cover within each site that would be used to compare UAS derived estimates. Guided loosely by the Gibbes et al. (2010) implementation of the Walker (1976) transect protocol, a random angle was chosen at each site using a stopwatch to determine the azimuth from the flight location for each random transect. This transect was then walked in both directions from center, stopping in ten meter intervals (Figure 4). At each stop, the nearest woody individual within a five meter radius was located and stem location was recorded using a Garmin R1 GNSS receiver (Garmin, Olathe, KS, USA). Heights were estimated by taking the mean of three height measurements 
taken using a Leica Disto 810 rangefinder and through measurements in four cardinal directions, crown radial measurements were recorded for each stem. This process resulted in ten opportunities at each reference site from which to collect height and canopy extent measurements to compare to UAS estimates, totaling 30 opportunities for each savanna vegetation cover category.

Location and crown metrics were then converted into .shp format using a toolchain in the $\mathrm{R}$ programming environment utilizing the gdal library. This process allowed for in situ measurements translated into a shapefile to be directly compared to output vectors from analyses described in the following sections. Due to low location accuracy of the GNSS receiver relative to the spatial grain of the imagery collected, in situ crowns were moved by hand to lie directly over the individuals measured in the field.

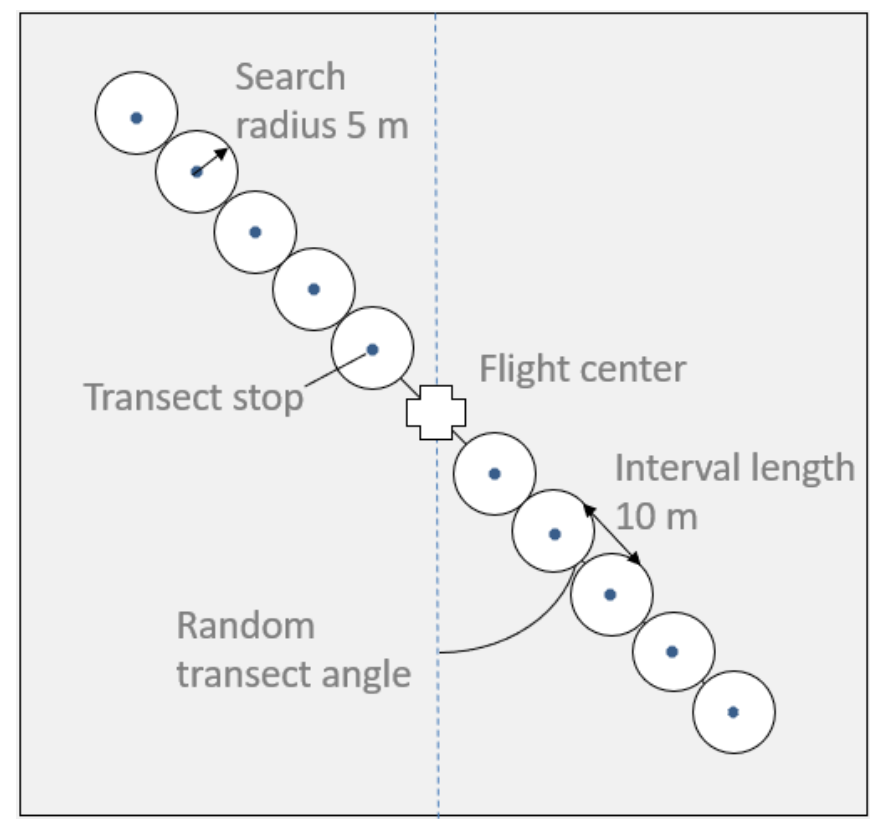

Figure 4. Field sampling protocol guided loosely by Gibbes et al. (2010). A random angle used dictated the direction of the transect walked. Along the transect, stops were made in ten meter intervals where the nearest woody individual within a five meter radius was located and height and crown estimates were recorded. 


\section{Delineation methods}

As the two pervasive methods for image segmentation, this study chose to compare outputs between implementations of a boundary-based and region growing algorithms. Using identical input data, methodological comparisons were made using the implementations written for analysis of LiDAR point clouds in the R package lidR.

\section{Watershed Segmentation}

Densified point clouds for the RGB Mavic imagery as well as each narrowband sensor of the Sequoia were processed using the aforementioned Pix4DMapper workflow. To produce 2D canopy height models (CHM) for each data set, the DTM was subtracted from the DSM as described in figure 2. Each CHM was then analyzed using an implementation of a watershed segmentation algorithm within the lidR package. This exemplifies a boundarybased algorithm, identifying strong gradients throughout datasets using thresholds provided through the use of the second derivatives exhibiting both magnitude and direction of change (Jin 2012). Through this local aggregation of cells via the definition of boundaries, rasterized maps for each data set within each site were produced that could then be converted to polygon vectors. Heights extracted from the CHM and crown areas of each estimated tree vector could then be used for proceeding analysis.

\section{Region Growing Segmentation}

Similar to the watershed algorithm, CHMs were analyzed using the lidR package to delineate individual tree crowns using a region-growing implementation. In contrast to the aforementioned tool, the itcSegment algorithm (known as dalponte2016 in the lidR package) 
is considered to be a "tree-centric" approach (Coomes et al. 2017) that relies on similarity properties rather than within image differences to create output vectors for each estimated tree crown. A low-pass filter is applied to a rasterized CHM to reduce noise among the data. Local maxima are then identified to determine likely stem locations within the study region. This algorithm also leverages height to variably shift search extents for crown edges dependent upon local maxima. Known as variable window filtering (VWF), this process adjusts expectations for crown extent based upon heights of detected crowns to mitigate problems of under-segmentation for small trees and shrubs and over-segmentation for taller trees that possibly exhibit multiple maxima (Nunes et al. 2017). To fit a model to be used for VWF, height and crown data were used from both grass- and tree-dominated sites. A decision made to omit shrub-dominated sites seeks to remove woody individuals that are less representative of those found among all study sites and to eliminate the possibility of erroneous field measurements where individuals sampled were very difficult to access and measure. Due to the highly skewed nature of these data, the data required a square root transform to fulfill the assumption of normality among residuals, resulting in equation (1).

$y=0.857+0.426 h+0.053 h^{2}$

User defined thresholds help guide the region-growing process, while neighboring pixels are searched to determine canopy extent. Two growing thresholds used are user defined values between 0 and 1 . The first is the value at which a pixel is added to a region if its height is greater than the tree height multiplied by this value. The second is the value where a pixel is added to a region if its height is greater than the current mean height of the 
region multiplied by this value (Dalponte and Coomes 2016). These parameters were iteratively tested using an RGB point cloud as the baseline to determine those producing estimates that best represent woody individuals in the study sites. A qualitative assessment of all parameter combinations in intervals of 0.2 revealed that the lowest thresholds for both parameters were most inclusive and least fragmented leading to crown estimates that more accurately capture the field observations (Figure 5).
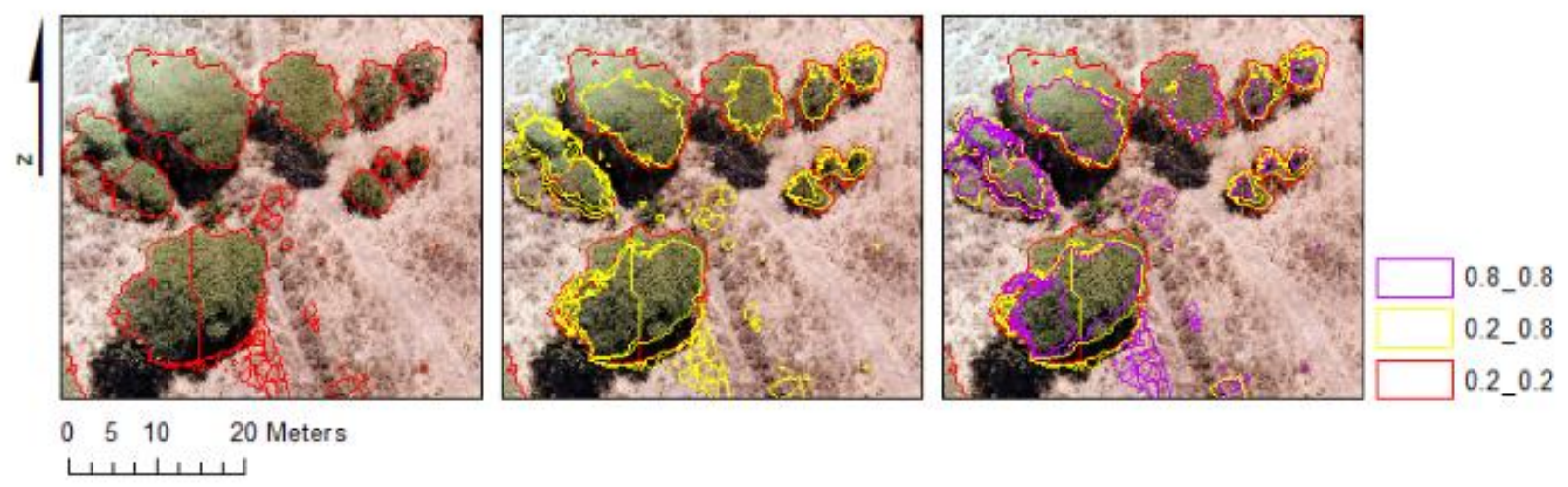

Figure 5. Results of parameter testing using the Dalponte 2016 region growing implementation. Lowest values $(0.2,0.2)$ best capture crowns in their entirety and deemed most useful for describing vegetation structure in this environment.

\section{Height Thresholding}

Representing a simpler approach, each CHM was analyzed using height information alone without consideration of neighboring pixels. Following Fisher et al. (2014), all pixels with height values greater than three meters were classified as "tree", from one to three meters as "shrub", and below one as "other". This process serves as a baseline to which the other more complicated methods can be compared with regards to structural classes. Results of this method cannot, however, be compared to in situ measurements for the delineation of individual crowns. 


\section{Assessment}

The first test of the efficacy of the previous delineation methods requires an assessment of disagreement globally. Following Pontius and Millones (2011), quantity disagreement $(2,3)$ and allocation disagreement $(4,5)$ for category $g$ and $J$ categories across each reference site. These measures of disagreement are meant to describe performance of delineation of structural vegetation classes. Using GIS, 100 random points in each study area were generated and visually classified using the high resolution orthoimagery collected with the micro-UAS. Land covers included "tree", "shrub", or "other". The boundary-based and region-growing methods can then be objectively tested against the simple height threshold layer. Using a confusion matrix, these measures seek to describe the disagreement between estimates and the analyst-classified data in a straightforward manner. As Pontius and Millones (2011) suggest, the kappa family of indices are inadequate statistics for describing agreement in land cover analysis for several reasons. Kappa can lead to overestimation of chance agreement leading to underestimation of classification accuracy (Foody 1992), which begs the question if chance evaluation is even necessary (Turk 2002).

Equation (2) calculates the quantity disagreement for category $g$. In this equation, the proportion of category $g$ in the comparison map (algorithm output) is subtracted from the proportion of category $g$ in the reference map (analyst classified). Equation (3) is responsible for overall quantity disagreement for $J$ categories present in the study area. Since an overestimation in one category always results in underestimation of another, the sum of all quantity disagreements must be divided by two. Allocation disagreement is calculated in equation (4) for an arbitrary category $g$, where the first argument of the minimum function is the omission of category $g$ and the second accounts for the commission. Because omission 
and commission occur in pairs, this function must be multiplied by two and the pairing is limited by the minimum of the two proportions. Just as equation (3) must account for double counts as the summary statistic, equation (5) similarly sums allocation agreements for $J$ categories and divides by two. Equation (6) is the total disagreement calculated by summing overall quantity and allocation disagreements.

$q_{g}=\left|\left(\sum_{i=1}^{J} p_{i g}\right)-\left(\sum_{j=1}^{J} p_{g j}\right)\right|$

$Q=\frac{\sum_{g=1}^{J} q_{g}}{2}$

$a_{g}=2 \min \left[\left(\sum_{i=1}^{J} p_{i g}\right)-p_{g g,}\left(\sum_{i=1}^{J} p_{g j}\right)-p_{g g}\right]$

$A=\frac{\sum_{g=1}^{J} a_{g}}{2}$

$D=Q+A$

Regarding differences within sites and vegetation groups, various outputs were compared using Spearman's Rank correlation coefficient (Equation 7). Rather than regressing, this statistic was chosen to describe agreement between datasets that are known to be error-prone. In situ measurements are estimates themselves and used as the baseline to compare UAS estimates in terms of agreement rather than assess the ability to predict one 
from the other. Individuals from each of the polygon output layers were selected through an automated tool-chain implemented in the Python 2.7 environment using arcpy tools (ESRI, Redlands, CA) (Figure 6). Where the recorded in situ stem location fell within a delineated crown, that crown served as the representative for comparison. Otherwise, the nearest delineated crown that intersected or lied within the in situ crown measurement was used.

$r_{s}=1-\frac{6 \sum d_{i}^{2}}{n\left(n^{2}-1\right)}$

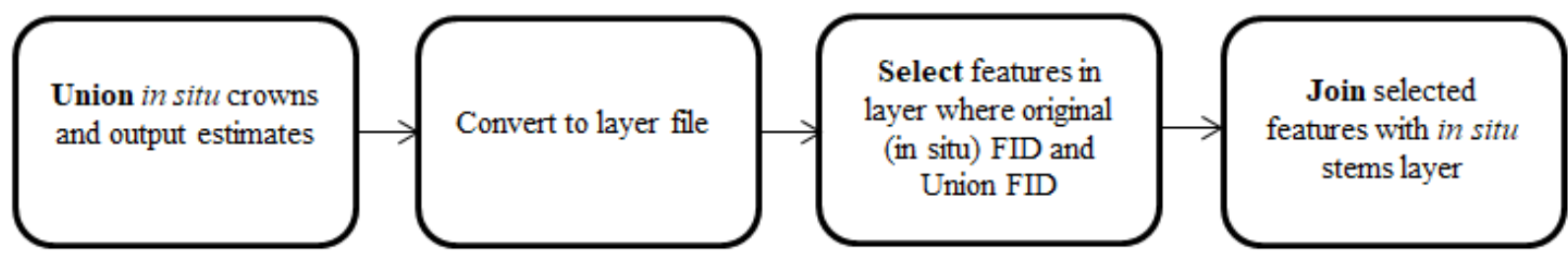

Figure 6. Algorithm result estimate selection tool-chain for in situ comparison implemented using the arcpy package in a Python 2.7 environment. A relationship between algorithm estimates and in situ measurements is created using the union tool. A selection query on these features establish where the in situ and union feature IDs are identical. The selected features and attributes are then joined to the in situ stems layer, which now contains algorithm estimates as well as in situ measurements. 


\section{RESULTS}

\section{Data Processing Results}

\section{In Situ Measurements}

The field sampling protocol provided opportunities for ten in situ representatives at each site. Table 3 provides descriptive statistics for all in situ measurements for height and crown area of samples at grass-, shrub-, and tree-dominated sites. As expected, height metrics consistently increase with increasing woody cover, as do mean crown areas. Plot heterogeneity is also captured through these statistics, with F4003 (shrub-dominated) exhibiting the highest degree of height variability $(\mathrm{CV}=2.77)$ and $\mathrm{A} 2201$ (tree-dominated) the greatest variability in terms of crown area $(\mathrm{CV}=2.12)$.

Due to the highly variable nature of savanna environments in terms of species and woody density, samples did not always contain ten individuals for comparison, particularly in grassy sites where there is often little woody vegetation. Conversely, where the nearest individual within the five meter radius was a member of the understory, we also measured the individual with the occluding canopy, leading to the varying $n$ sizes observed in Table 3 . 


\begin{tabular}{|c|c|c|c|c|c|c|c|c|c|c|}
\hline & \multirow[b]{2}{*}{ Site } & & \multicolumn{4}{|c|}{ Height } & \multicolumn{4}{|c|}{ Crown } \\
\hline & & $n$ & $\begin{array}{l}\text { Mean } \\
\text { height }\end{array}$ & $\begin{array}{l}\text { Max } \\
\text { height }\end{array}$ & $S D$ & $C V$ & $\begin{array}{c}\text { Mean crown } \\
\text { area }\end{array}$ & $\begin{array}{c}\text { Max } \\
\text { crown }\end{array}$ & $S D$ & $C V$ \\
\hline \multirow{3}{*}{ Grass } & $A 2200$ & 7 & 2.13 & 4.35 & 1.35 & 0.64 & 5.95 & 27.98 & 10.01 & 1.68 \\
\hline & $F 4000$ & 6 & 0.82 & 1.36 & 0.27 & 0.34 & 1.61 & 5.09 & 1.84 & 1.14 \\
\hline & N1004 & 4 & 2.44 & 5.76 & 2.26 & 0.93 & 6.28 & 21.62 & 10.25 & 1.63 \\
\hline \multirow{3}{*}{ Shrub } & $A 2002$ & 10 & 2.10 & 3.09 & 0.61 & 0.29 & 4.20 & 13.81 & 3.64 & 0.87 \\
\hline & $F 4003$ & 10 & 2.21 & 16.69 & 6.12 & 2.77 & 9.89 & 41.22 & 16.37 & 1.66 \\
\hline & K101 & 10 & 2.04 & 2.52 & 0.64 & 0.31 & 22.33 & 54.08 & 16.36 & 0.73 \\
\hline \multirow{3}{*}{ Tree } & $A 2100$ & 8 & 12.60 & 18.00 & 4.41 & 0.35 & 162.42 & 463.35 & 136.72 & 0.84 \\
\hline & $A 2102$ & 11 & 5.00 & 11.59 & 4.15 & 0.83 & 24.45 & 74.74 & 31.51 & 1.29 \\
\hline & $A 2201$ & 10 & 5.18 & 14.46 & 4.03 & 0.78 & 46.88 & 314.20 & 99.32 & 2.12 \\
\hline
\end{tabular}

Table 3. Summary of in situ measurements for each study site flown. It was not uncommon for fewer than 10 individuals to be recorded (particularly in grass-dominated sites) despite 10 transect stops due to the highly variable nature of the vegetation in these savannas. Where nearest individuals were obfuscated in the understory, the overstory individual metrics were also recorded and included in analysis.

\section{Point cloud densities}

Point clouds and concomitant two-dimensional products resulting from Pix4D processing vary between sensors, bands, and sites (Table 4). Most notably, the largest differences are observed between sensors. RGB point clouds range from 154.22 points $/ \mathrm{m}^{2}$ (A2102, tree-dominated) to 362.08 points $/ \mathrm{m}^{2}$ (F4000, grass-dominated) and discrete band point clouds from the Parrot Sequoia range from 9.49 points $/ \mathrm{m}^{2}$ (A2102, tree-dominated, green band) to 16.25 points $/ \mathrm{m}^{2}$ (A2200, grass-dominated, NIR band).

Similarly, GSD varies across all data with the largest differences between sensors. RGB products exhibit GSDs ranging from 3.32 cm (N1004, grass-dominated; F4003, shrubdominated) to $3.59 \mathrm{~cm}$ (A2002, shrub-dominated) while multispectral data ranges from 10.15 cm (A2100, tree-dominated, NIR band) to $10.65 \mathrm{~cm}$ (F4000, grass-dominated, green band). Resolution differences can be seen in figure 7. 

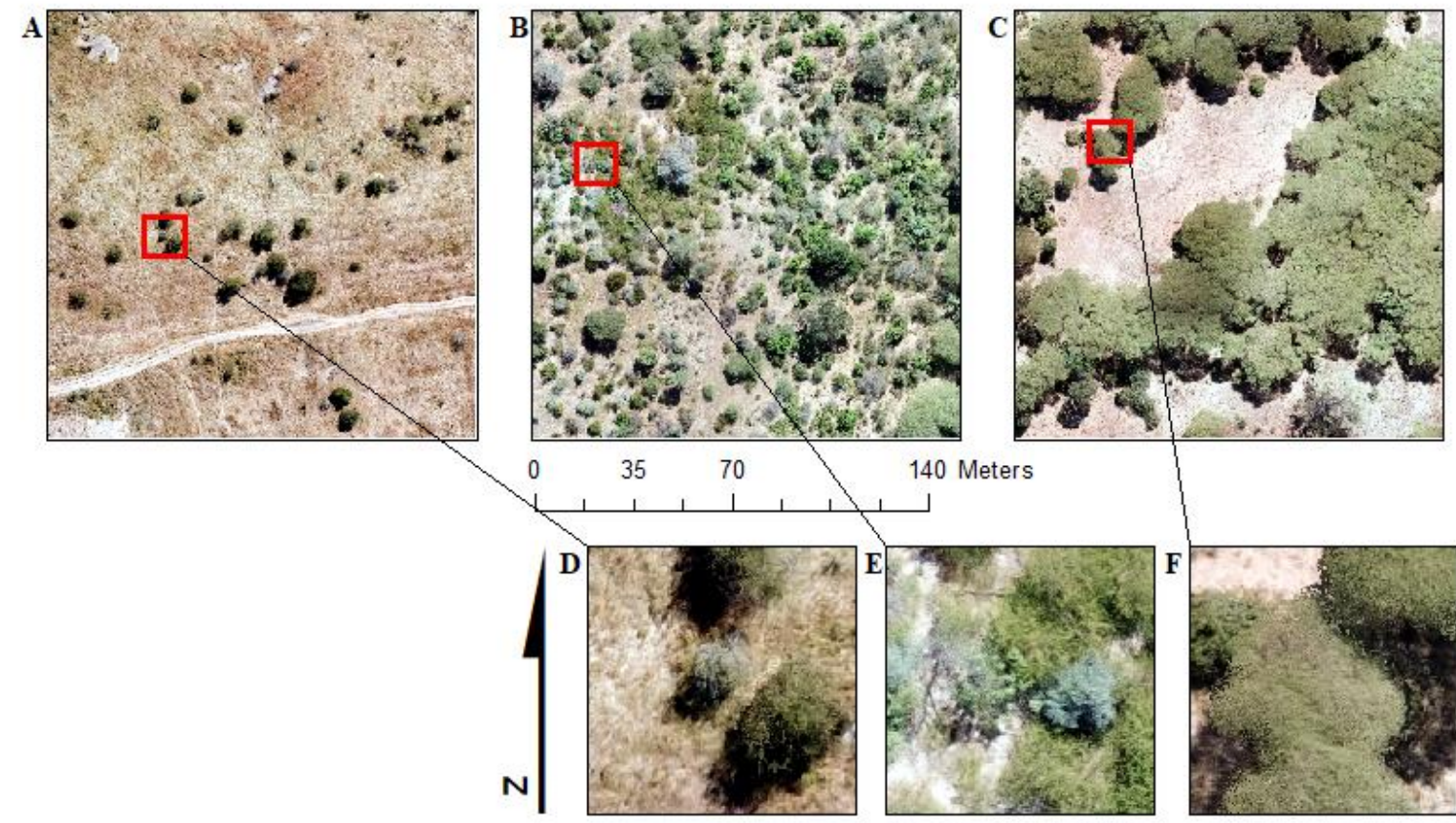

$0 \quad 2.5 \quad 5$

10 Meters

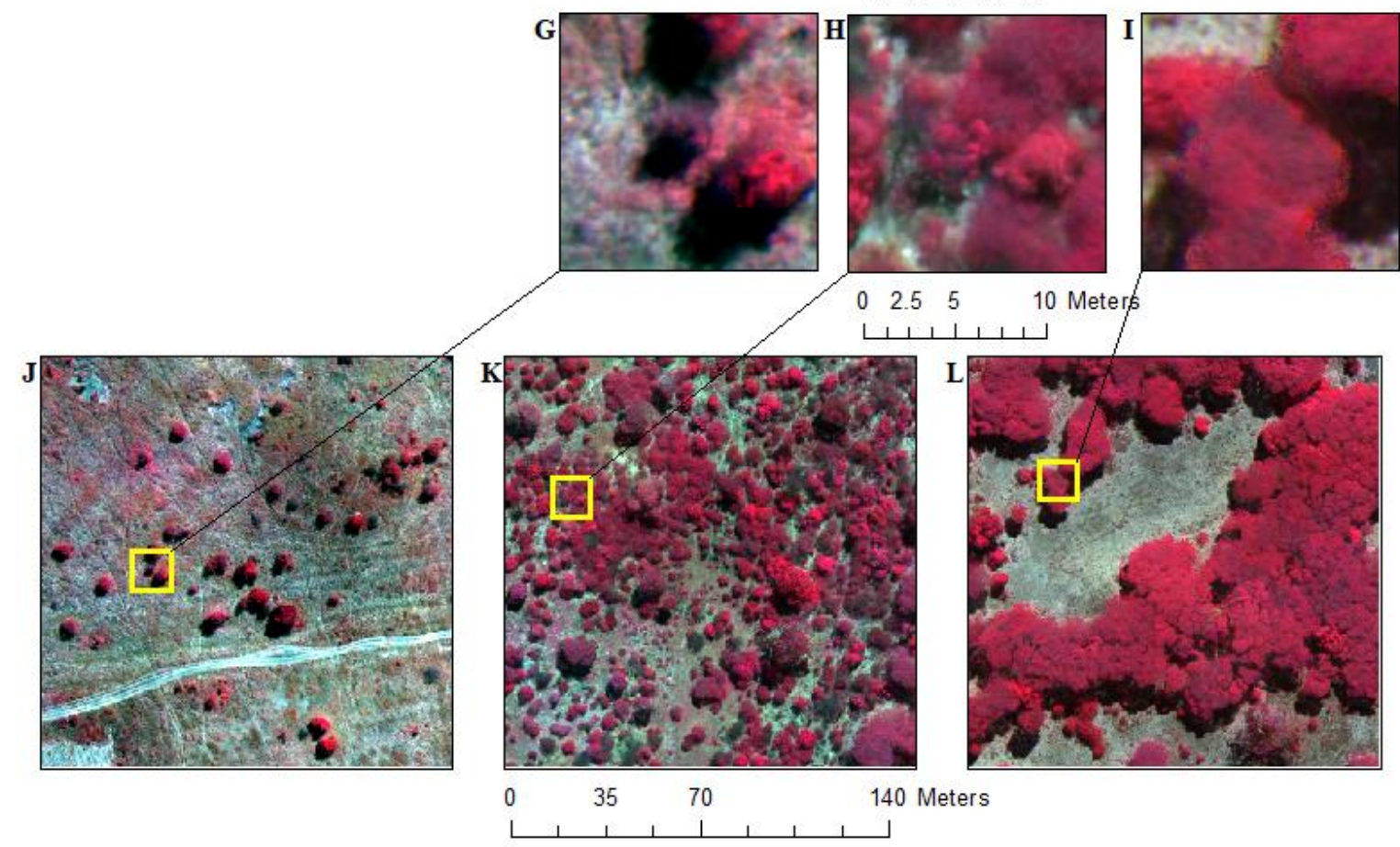

Figure 7. Examples of orthomosaics for grass- (A,D,G,J), shrub- (B,E,H,K), and tree-dominated sites (C,F,I,L). Panels A-F represent RGB data collected via the stock Mavic sensor and G-L are false color composites assembled from discrete bands (green, red, near infrared) of Parrot Sequoia data. 


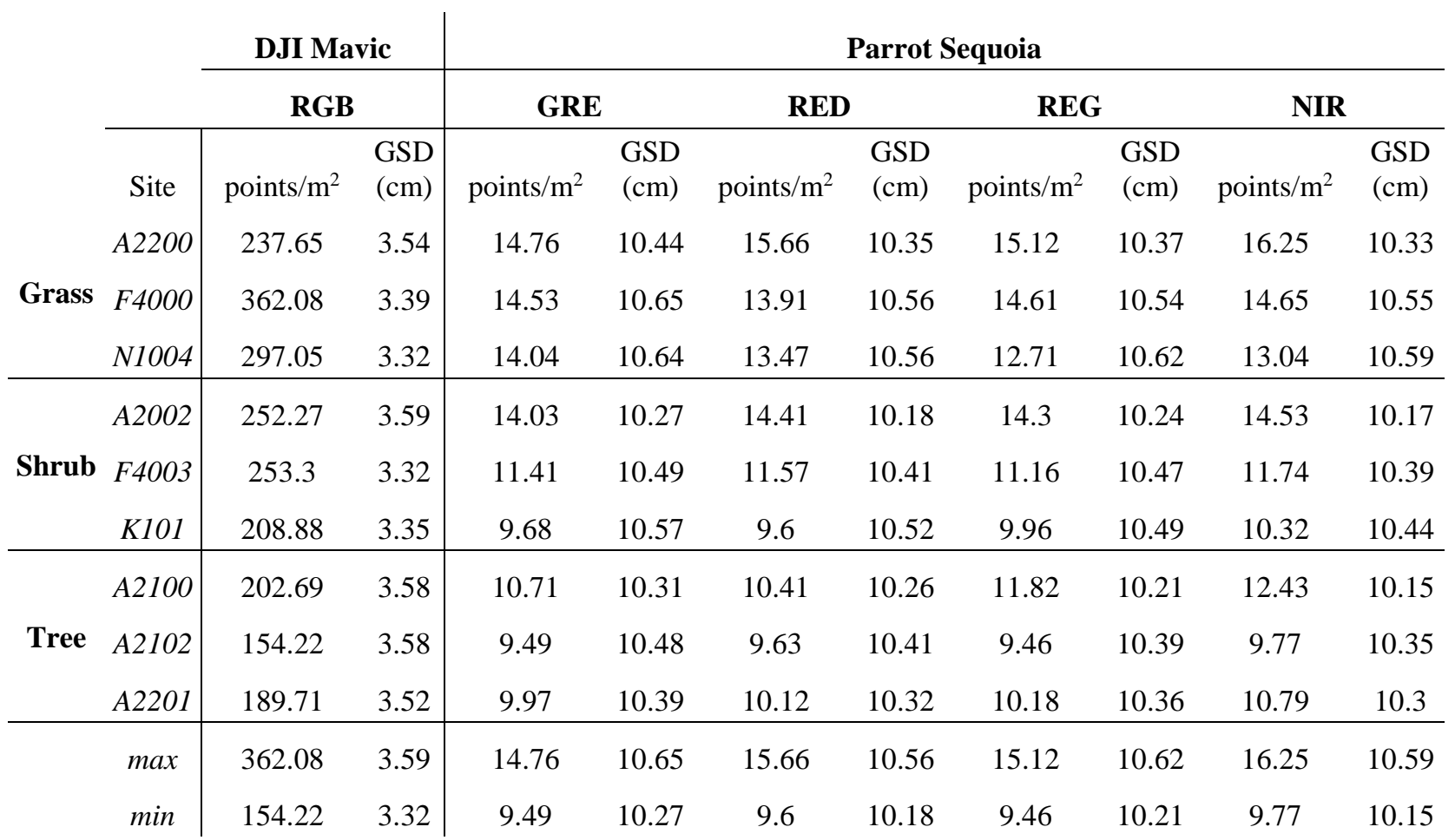

Table 4. Point cloud densities and GSD for each dataset from all sites flown.

\section{Quantity and Allocation Disagreement}

Results of the disagreement assessment between methods reveal the simplest method, height thresholding, as the method with the least disagreement between expert classified points and model estimations $(D=0.12)$ (Table 5). However, in grass-dominated sites, the region growing implementation minimized all error metrics for woody classified points $(Q=$ 0.003, $A=0, D=0.003$ ) Table 6). Among shrub-dominated sites, the simple height threshold minimized errors of quantity error and total error across all three classes. In tree-dominated sites, the region-growing algorithm exhibits the lowest quantity error of the three methods for the "tree" class, with thresholding and watershed methods superior for "shrub" and "other" 
classes respectively (Table 6). Total disagreement in tree-dominated sites is minimized in "tree" and "shrub" classes by the thresholding method, while the watershed method exhibits slightly lower total disagreement among points classified as "other".

\begin{tabular}{cccc} 
& $Q$ & $A$ & $D$ \\
\hline Watershed & 0.141 & $\mathbf{0 . 0 2 7}$ & 0.168 \\
Dalponte & 0.119 & 0.041 & 0.16 \\
Threshold & $\mathbf{0 . 0 7 7}$ & 0.043 & $\mathbf{0 . 1 2}$
\end{tabular}

Table 5. Quantity, allocation, and disagreement totals for pooled outputs.

When sites are pooled, the tree-centric approach shows lowest quantity disagreement among points classified as "tree" $(Q=0.024$, Table 8$)$, but the simple height threshold has lowest values for this metric in the "shrub" and "other" classes $(Q=0.043, Q=0.077$, Table 9) as well as overall quantity disagreement $(Q=0.0765$, Table 7$)$. 


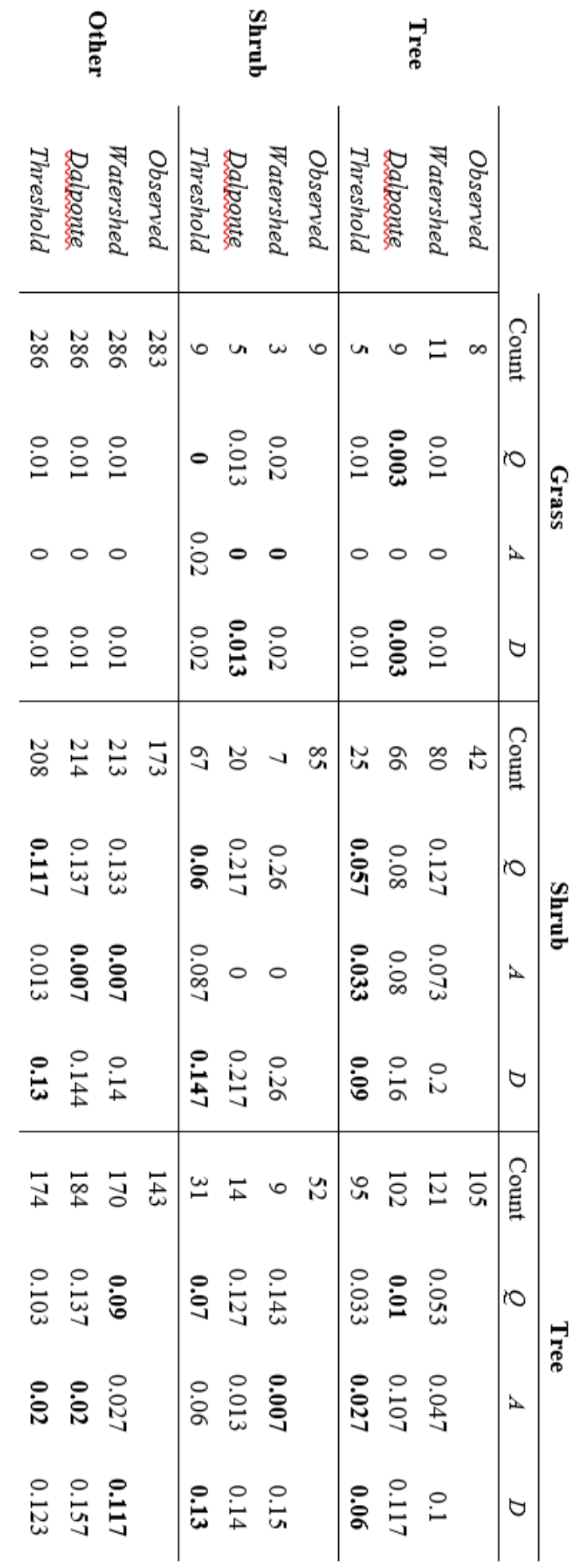

Table 6. Quantity and allocation disagreement for a boundary-based method (watershed), a region growing implementation (dalponte2016), and a simple height threshold each performed on CHMs for each site and sensor. Rows represent counts and disagreements between hand classified points and model estimates. 


\begin{tabular}{cccccc} 
Watershed & \multicolumn{5}{c}{ Estimate } \\
\hline \multirow{3}{*}{ Observed } & Tree & Shrub & Other & SUM \\
\hline \multirow{7}{*}{ Tree } & 0.152 & 0 & 0.02 & 0.172 \\
& Shrub & 0.079 & 0.02 & 0.063 & 0.162 \\
& Other & 0.004 & 0.001 & 0.66 & 0.666 \\
& SUM & 0.236 & 0.021 & 0.743 & 1 \\
\hline & $Q$ & 0.063 & 0.141 & 0.078 & 0.141 \\
& $A$ & 0.04 & $\mathbf{0 . 0 0 2}$ & 0.011 & $\mathbf{0 . 0 2 7}$
\end{tabular}

Table 7. Confusion matrix and quantity and allocation disagreements for pooled watershed outputs. Bolded values denote lowest error of all methods.

\begin{tabular}{cccccc} 
Dalponte2016 & \multicolumn{5}{c}{ Estimate } \\
\hline \multirow{3}{*}{ Observed } & & Tree & Shrub & Other & SUM \\
\hline & Tree & 0.138 & 0 & 0.034 & 0.172 \\
& Shrub & 0.057 & 0.041 & 0.064 & 0.162 \\
& Other & 0.002 & 0.002 & 0.661 & 0.666 \\
& SUM & 0.197 & 0.043 & 0.76 & 1 \\
\hline & $Q$ & $\mathbf{0 . 0 2 4}$ & 0.119 & 0.094 & 0.119 \\
& $A$ & 0.069 & 0.004 & $\mathbf{0 . 0 0 9}$ & 0.041
\end{tabular}

Table 8. Confusion matrix and quantity and allocation disagreements for pooled region-growing (Dalponte 2016) outputs. Bolded values denote lowest error of all methods.

\begin{tabular}{cccccc} 
Threshold & \multicolumn{5}{c}{ Estimate } \\
\hline \multirow{4}{*}{ Observed } & Tree & 0.129 & Shrub & Other & SUM \\
\hline & Shrub & 0.01 & 0.091 & 0.021 & 0.172 \\
& Other & 0 & 0.006 & 0.66 & 0.666 \\
& SUM & 0.139 & 0.119 & 0.742 & 1 \\
\hline & $Q$ & 0.033 & $\mathbf{0 . 0 4 3}$ & $\mathbf{0 . 0 7 7}$ & $\mathbf{0 . 0 7 7}$ \\
& $A$ & $\mathbf{0 . 0 2}$ & 0.056 & 0.011 & 0.044
\end{tabular}

Table 9. Confusion matrix and quantity and allocation disagreements for pooled height threshold outputs. Bolded values denote lowest error of all methods. 
The simple height thresholding method proved to be the best method for minimizing total and quantity disagreements globally using RGB CHM as input data (Table 5). As was the case, this method was extended to CHMs created from each band of the Parrot Sequoia multispectral sensor as well. Pooled site data were used to compare visually classified points for "other", "shrub", and "tree" classes to estimates of point clouds based on height threshold outputs (Table 9). Quantity disagreement is minimized in all classes within the three site types for NIR data $(Q=0.068, Q=0.04$, and $Q=0.028$ for "other", "shrub" and "tree" classes respectively). Among points classified as "shrub", the RGB data show lowest allocation and overall disagreements $(A=0.056, D=0.099)$, but in both other classes, "other" and "tree", data collected beyond the visible portion of the spectrum best show lowest disagreement with visually classified points $($ Dreg $=0.085$, Dnir $=0.044$ for "other" and "tree" classes respectively). When aggregating all classes, the point-rich RGB data show the lowest overall error quantified ( $D=0.12$, Table 10$)$, while NIR data show lowest quantity disagreement $(Q=0.69)$ and red the lowest allocation disagreement $(A=0.039)$. Vegetation coverage visualizations using the NIR data are shown in figure 8.

\begin{tabular}{cccccccccc} 
& \multicolumn{3}{c}{ Other } & \multicolumn{3}{c}{ Shrub } & \multicolumn{3}{c}{ Tree } \\
\cline { 2 - 10 } & $Q$ & $A$ & $D$ & $Q$ & $A$ & $D$ & $Q$ & $A$ & $D$ \\
\hline RGB & 0.077 & 0.011 & 0.088 & 0.043 & $\mathbf{0 . 0 5 6}$ & $\mathbf{0 . 0 9 9}$ & 0.033 & 0.02 & 0.053 \\
Green & 0.09 & 0.009 & 0.099 & 0.053 & 0.071 & 0.124 & 0.037 & 0.022 & 0.059 \\
Red & 0.138 & $\mathbf{0 . 0 0 2}$ & 0.14 & 0.077 & 0.062 & 0.139 & 0.061 & $\mathbf{0 . 0 1 3}$ & 0.074 \\
Red Edge & 0.069 & 0.016 & $\mathbf{0 . 0 8 5}$ & $\mathbf{0 . 0 4}$ & 0.071 & 0.111 & 0.029 & 0.022 & 0.051 \\
NIR & $\mathbf{0 . 0 6 8}$ & 0.029 & 0.097 & $\mathbf{0 . 0 4}$ & 0.076 & 0.116 & $\mathbf{0 . 0 2 8}$ & 0.016 & $\mathbf{0 . 0 4 4}$
\end{tabular}

Table 10. Quantity and allocation disagreement totals of pooled outputs for each band with respect to points classified as "other", "shrub", or "tree". 


\begin{tabular}{cccc} 
& $Q$ & $A$ & $D$ \\
\hline RGB & 0.077 & 0.044 & $\mathbf{0 . 1 2}$ \\
Green & 0.09 & 0.051 & 0.141 \\
Red & 0.138 & $\mathbf{0 . 0 3 9}$ & 0.177 \\
Red Edge & 0.069 & 0.055 & 0.124 \\
NIR & $\mathbf{0 . 0 6 8}$ & 0.0605 & 0.129
\end{tabular}

Table 11. Quantity and allocation disagreement totals for pooled band outputs.
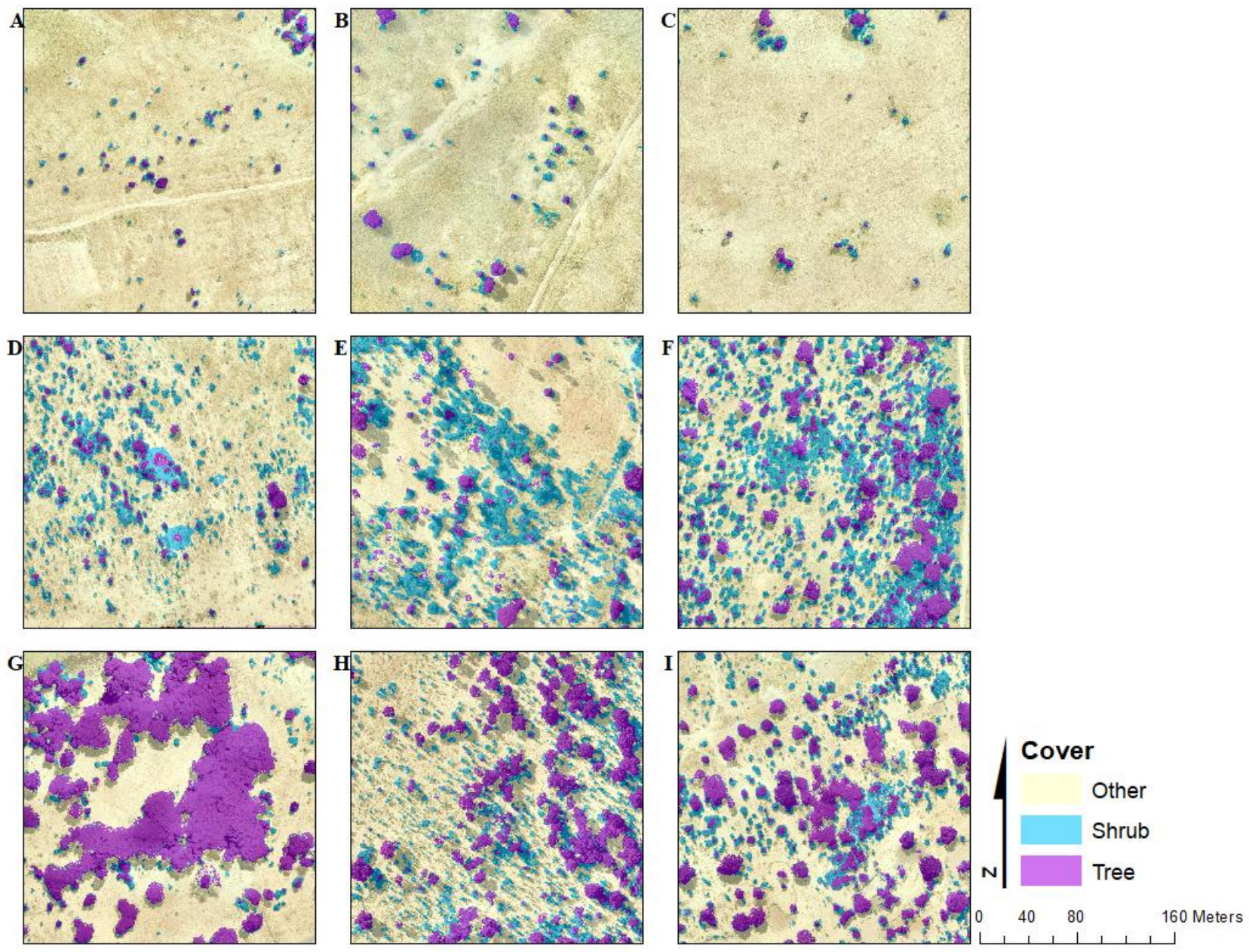

Figure 8. Vegetation cover classification across grass- (panels A-C), shrub- (panels D-F), and tree-dominated sites (panels G-I) utilizing the simple height threshold method and the NIR CHM. 


\section{Height and Crown Area Estimates}

Due to low $n$ values in some of the study sites, namely the grass-dominated sites, data were pooled for analysis. With both the watershed and dalponte2016 algorithms, highest overall $n$ values were observed using RGB point clouds, identifying 56 of 76 woody individuals measured in the field with each method. Among Sequoia bands, the results were consistent between methods with respect to the number of in situ measurements represented by estimates. NIR point clouds identified 53 for each method, red-edge 51 and 50, green 48 and 46, and red 45 and 41 for watershed and dalponte2016 methods respectively (Figures 8 and 9).

All point clouds exhibit statistically significant correlations with in situ measurements for both methods $(p<0.05)$ but vary with respect to mean absolute errors (Figure 9). Between methods, all sequoia bands show decreased MAE when using the region-growing implementation versus the watershed segmentation, while the RGB data shows an increase in this error metric. The lowest MAE values were observed in the red edge data for the watershed segmentation $(\mathrm{MAE}=2.18 \mathrm{~m})$ and red using the tree-centric approach $(\mathrm{MAE}=$ $1.55 \mathrm{~m})$

Crown areas were log transformed in an attempt to normalize the errors among in situ measured individuals that varied greatly in size. All estimate outputs from both methods prove to be statistically significant $(p<0.05)$ with respect to agreement with in situ measured crown areas, but again show major variation in MAE. As captured by the plots, the watershed segmentation both under and over-predicted crown areas at greater magnitudes than did the region-growing implementation (Figure 10, Figure 11). Every point cloud shows a substantial decrease in MAE when using the tree-centric approach. RGB output for the 
watershed segmentation exhibits the lowest error of all watershed estimates $(\mathrm{MAE}=$ $104.54 \mathrm{~m}^{2}$ ), but also the smallest difference in MAE between methods. Tree-centric crown area estimates using discrete spectral band input data all decreased MAE drastically compared to RGB data. The red point cloud shows the lowest value for this metric (MAE = $\left.49.68 \mathrm{~m}^{2}\right)$ as well as the strongest correlation with in situ measurements $(r=0.71)$. 

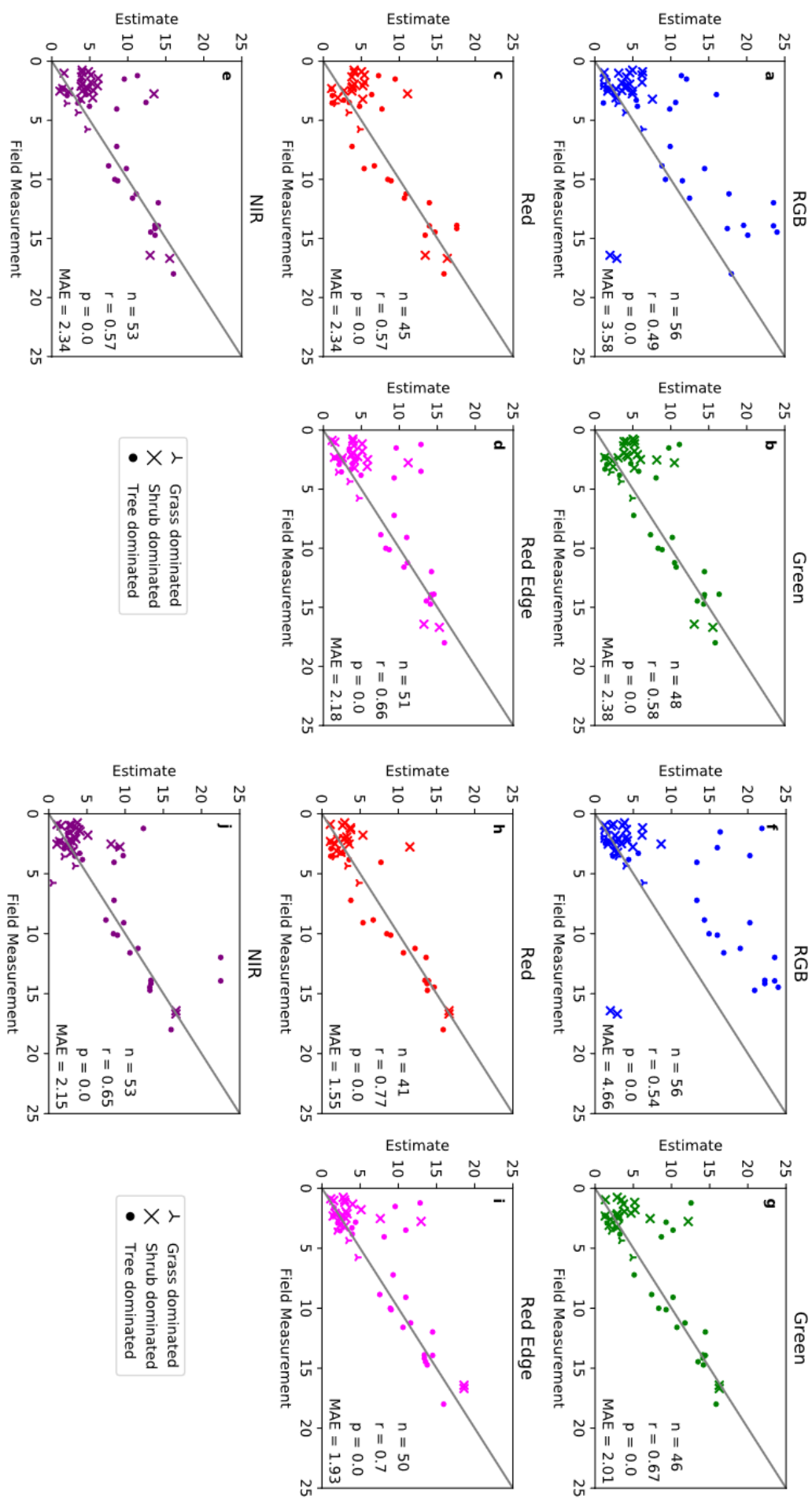

Figure 9. Comparisons of in situ height measurements and height estimates from the watershed segmentation (pan ${ }^{\text {els }} \mathrm{a}-\mathrm{e}$ ) and dalponte2016 region-growing segmentation (panels $\mathrm{f}-\mathrm{j}$ ) for respective point clouds. Sample sizes reflect individuals estimated by the algorithm that were also measured in situ. 

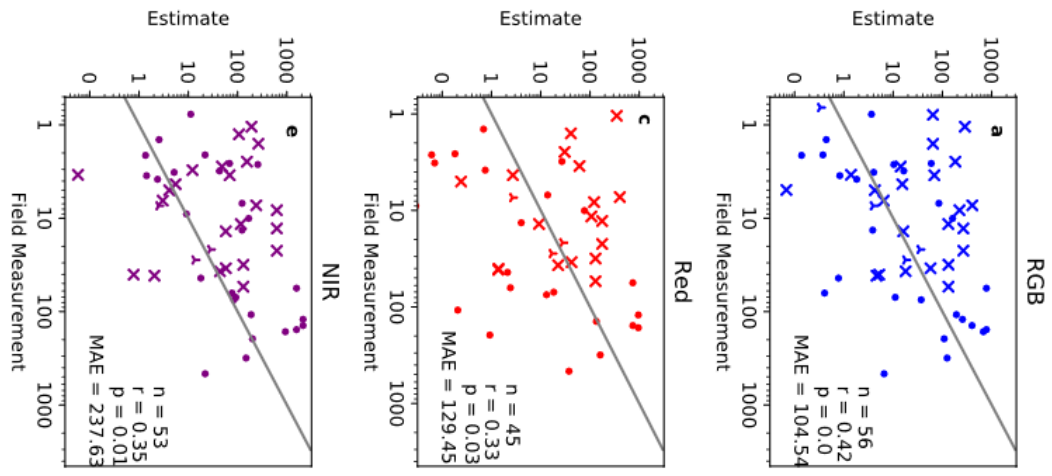

Estimate
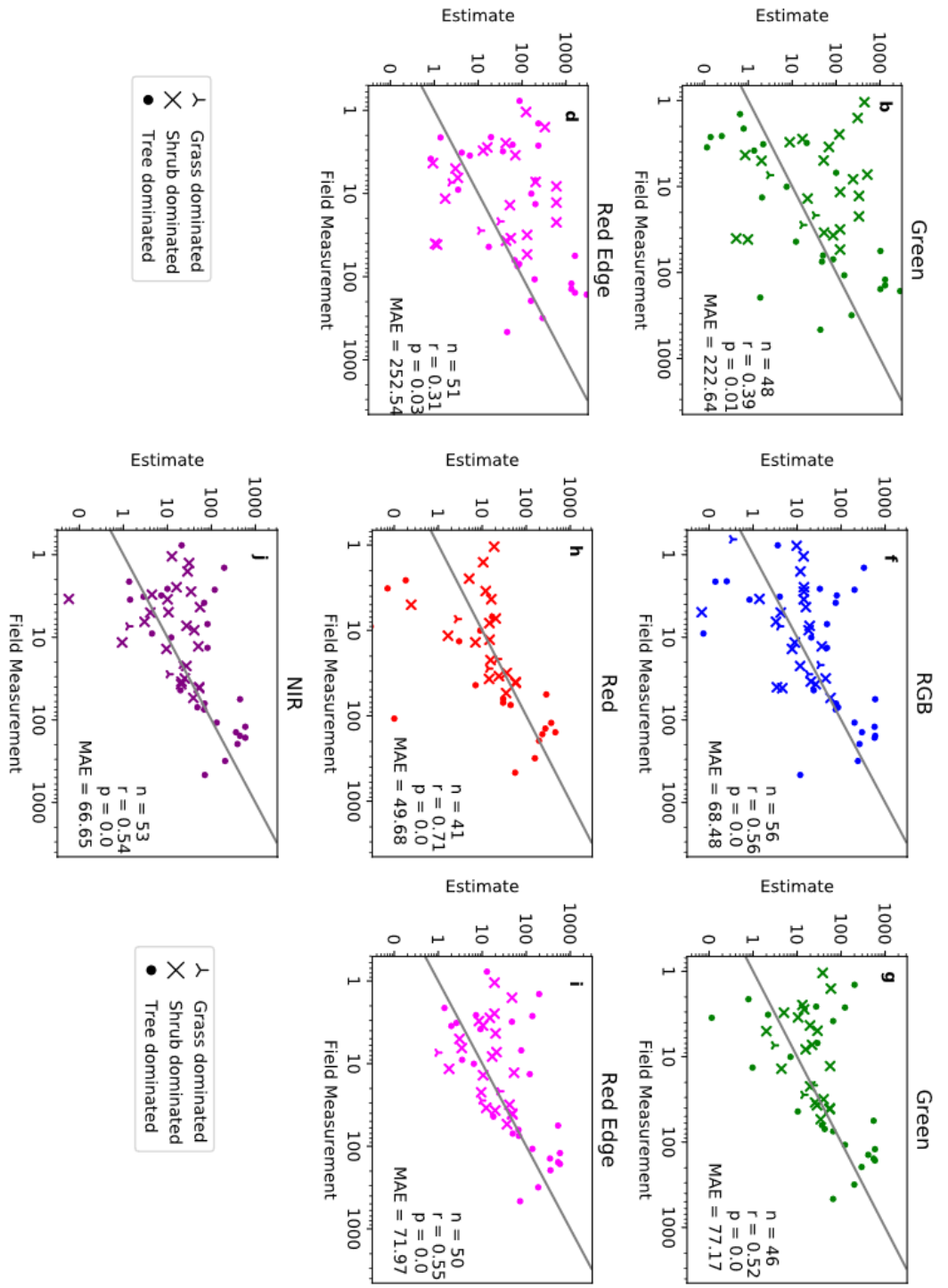

Figure 10. $\mathrm{Log} / \log$ comparisons of in situ height measurements and crown area estimates from the watershed segmentation (panels a - e) and dalponte2016 region-growing segmentation (panels $f-j$ ) for respective point clouds. Sample sizes reflect individuals estimated by the algorithm that were also measured in situ. 

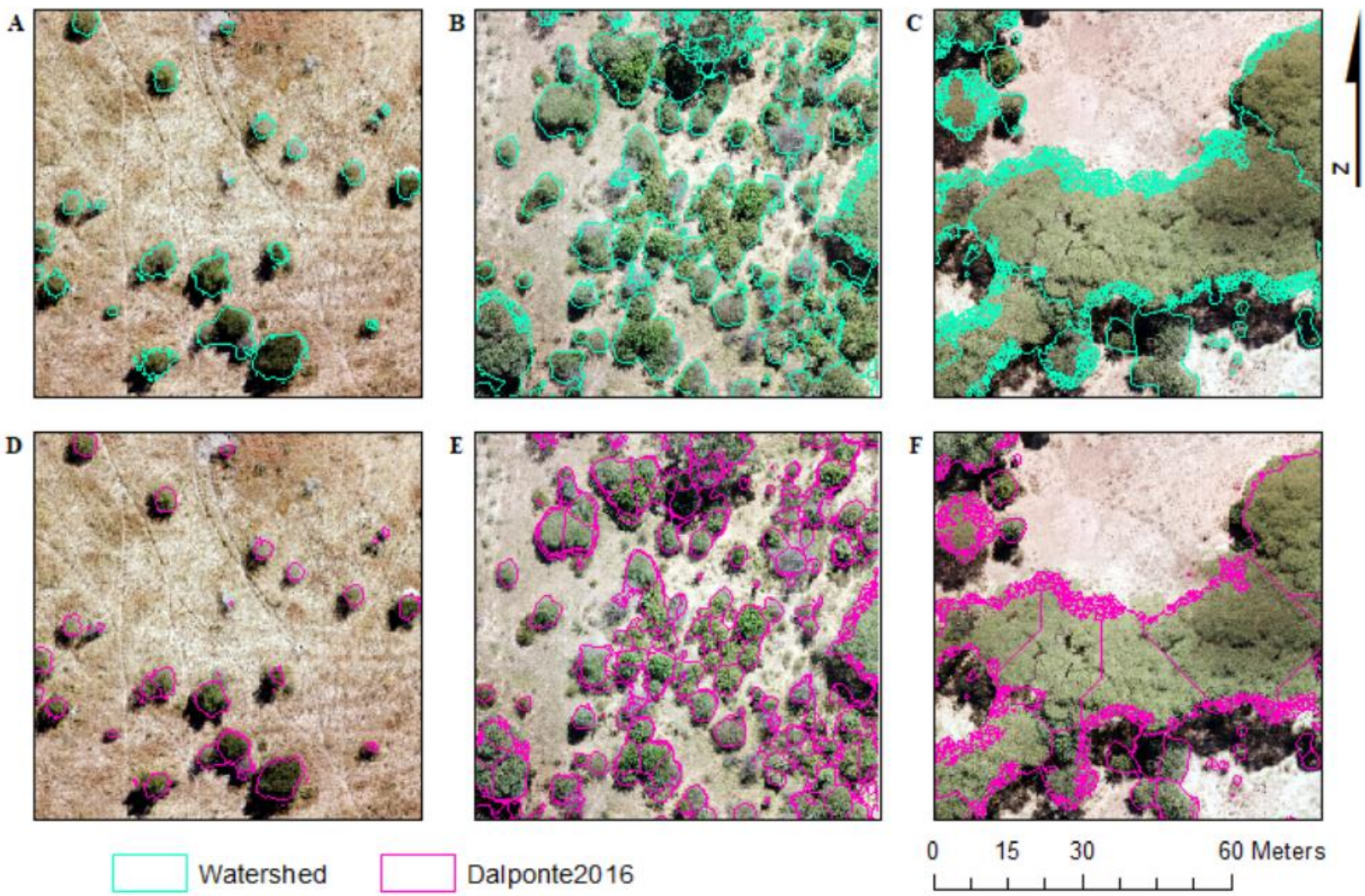

Figure 11. Visual comparison of watershed (boundary-based) (panels A, B, C) and dalponte2016 (regiongrowing) (panels D, E, F) algorithms as implemented from the lidR package. Note the difference between algorithms in the ability to distinguish between neighboring individuals. Also of note- the difficulty presented by Acacia tortilis stands (panels $\mathrm{C}$ and $\mathrm{F}$ ). 


\section{DISCUSSION}

\section{Quantity and Allocation Disagreement}

Results of the quantity and allocation disagreement analysis indicate that all methods perform well in grass-dominated sites but degrade as woody cover increases. This supports the hypothesis of the first research question in that grass-dominated sites with woody individuals that are easily distinguished by the human eye are also well delineated in an automated fashion. This result is consistent with efforts seeking to delineate discrete trees on a landscape (Bonnet, Leisin, and Lejeune 2017; Alonzo et al. 2018) as opposed to those in closed canopy conditions (Coomes et al. 2018).

The tree-centric region-growing algorithm outperformed the other methods in these sites despite the simple height thresholding proving to be more effective across all sites. This success may be attributable to the discrete nature of the boundaries of the individuals found in these sites, but also to the shortcomings of the height-thresholding method. With fewer opportunities, it is easily understood that the simplest method will fall short in terms of including the entire tree crown due to crown edges measured below three meters in height. The strength of the tree-centric approach is its inclusive nature of operation, iterating over neighboring cells to determine crown extent from a local maximum. This process emerges in the differences in quantity disagreement, as it is expected that the threshold will predict higher "shrub" proportions in these sites.

Despite the strength of the region-growing technique in the grass-dominated sites, the results imply that a simple height-threshold is the most robust method of those tested in this 
study for estimating woody cover and should continue to be used as a baseline of comparison (Fisher et al. 2014). Although the simplest design, this method should be favored for studies interested in quantifying extents of woody cover. However, the potential of slight overestimates in the shrub class should be noted, as edges of woody growth that function as trees below the user-defined threshold will contribute to shrub estimates.

With regards to quantity and allocation disagreement metrics, Warrens (2015) reminds users that values and application must be considered within the context of each study. Despite the contextual nature of any disagreement or accuracy metric, quantity and allocation disagreements lend direct insight to sources of error rather than focusing on overall correctness or possibility of agreement due to change as does overall Kappa. For this research, allocation error is likely subject to bias introduced via the visual classification be used to effectively compare either methods or input data based on the subjectivity involved with the random point classification. For instance, when points were visually classified as either "tree" or "shrub", heights of the individuals were largely unknown and classification is based only on expert opinion. Further, a woody individual can look and function as a shrub, but exceed three meters in height, leading to an automated classification as a tree, which would insert bias into both measures of disagreement.

With the possibility of analyst bias in the allocation error metric, results of the analysis of input data should be revisited, as the overall disagreement may be skewed leading to misinterpretation of results. With this possibility established, the hypothesis with regards to the second research question that data beyond the visible portion of the spectrum into the NIR can provide better estimates of vegetation structured can be considered. Height thresholding quantity disagreements for $\operatorname{NIR}(Q=0.068)$ and red edge $(Q=0.069)$ data are 
both lower than that of the RGB $(Q=0.077)$ data despite the point clouds being far less dense (Table 3). While all three output products are likely acceptable, the data into the NIR portion of the spectrum performed marginally better with maximum point densities (reg max $=15.12$ points $/ \mathrm{m}^{2}$, nir $\max =16.25$ points $/ \mathrm{m}^{2}$ ) being approximately $1 / 10$ that of the minimum RGB point density (154.22 points $\left./ \mathrm{m}^{2}\right)$.

While 100 meters has been shown to be the most appropriate flight altitude for RGB data (Fraser and Congalton 2018), this may not be the case for the multispectral bands of the Parrot Sequoia, and flights at a lower altitude may allow for more increased keypoint matching and denser point cloud production beyond the visible portion of the spectrum. This hypothesis would need to be tested, as Fraser and Congalton (2018) show point matching decreased at lower altitudes while flying a fixed wing aircraft. They attribute this decrease to lack of control over flight speed, however, which can be controlled with the use of a multirotor microcopter such as the DJI Mavic Pro, as similar vehicles have been shown to be effective for flight at lower altitudes (Dandois, Olano, and Ellis 2015).

Taking point densities into consideration, data in the NIR portion of the spectrum could be considered valuable in for this work. If multispectral sensors emerge in the near future that allow for similar GSD as collected in the visible portion of the spectrum, these results could help guide their use and enhance results for SfM studies seeking to derive point clouds that quantify vegetation structure across a landscape of interest.

\section{Crown Height and Area Comparisons}

In a more conspicuous manner, estimates using data beyond the visible portion of the spectrum more closely resemble heights of in situ crown measurements in terms of MAE 
using both boundary-based and region growing methods (Figure 9). These differences are open to interpretation, however, due to the varying sample sizes between bands of data. The RGB data with denser point clouds and finer GSD estimated more if the in situ individuals measured, but show higher error metrics and lower correlations. Further investigation is required to determine the individuals omitted from the Sequoia datasets, but judging from the scatter in Figure 9, it is likely coarser Sequoia products were unable to detect the smallest of the in situ shrubs (and sometimes forbs) measured. Moreover, a closer look could reveal that some (if not all) of individuals identified using RGB data are simply artifacts of both the sampling design as well as the automated workflow. A larger adjacent modeled crown could easily extend beyond its true extent to overlap its smaller neighboring shrub, which would be identified by the automated workflow outlined in Figure 6. This error source could also explain many of the height over-predictions among the scatter.

The comparison of methods in terms of crown area are fairly straightforward as shown in figures 10 and 11 . The boundary-based algorithm often struggles to capture true canopy extent which manifests as both under- and over-segmentations. With no constraints on extent, continuous shrub and tree covers will not be further subdivided and is often represented by one large aggregation of individuals. Conversely, in using the same method within the same scene, individuals exhibit multiple maxima, leading to over-segmentation and under-prediction of crown extent. This exercise exemplifies that the simpler boundarybased method is inadequate for extracting information about individuals in a highly heterogeneous savanna landscape, favoring the tree-centric approach that incorporates a variable window filter (VWF) for detecting maxima and ultimately limiting crown extent. 
Despite the incorporation of the VWF, the region-growing implementation is similarly confused in canopy edge areas (Figure 11c, 11f).

The $\log / \log$ transformations of the crown area plots highlight the shortcomings of the region-growing algorithm (Figure 10). Results are improved substantially from the watershed segmentation likely due to its integration of the VWF with a model fit from in situ measurements, but error in the low end of the scatterplot is particularly high compared to other residuals. Again, over-predictions are common and likely due to aggregations of multiple smaller shrubs or occlusion and false crown identification. With the tree-centric approach, despite lowest MAE observed among the red estimates $\left(\mathrm{MAE}=49.68 \mathrm{~m}^{2}\right)$, this band of data also only identified 41 of 76 individuals measured. The NIR and RGB estimates are similarly erroneous (MAEnir $=66.65 \mathrm{~m}^{2}, \mathrm{MAE} r g b=68.48 \mathrm{~m}^{2}$ ) but also represent larger proportions of the in situ measured crowns with 53 and 56 respectively.

It is clear that the region-growing implementation better represents crown areas than the boundary-based watershed algorithm, confirming the hypothesis from the third research question, but it cannot be concluded that either implementation is performing particularly well in the highly heterogeneous savanna sites of the Chobe Enclave. The vegetation varies greatly both among and within sites in terms of species and succession leading to difficulties fitting a model that can account for variation present. The most successful VWF applications are conducted on homogenous plots or plots with very few dominant species (Alonzo et al. 2018, Popescu and Wynne 2004), but consistent with this study, troubles are documented when trying to utilize this method in diverse plots (Coomes et al. 2017) and in areas with very dense vegetation (Nunes et al. 2017). 
Specific species, such as Acacia tortilis further complicate the use of automated approaches for delineation of individual tree crowns. These difficulties can be inferred from the estimated crowns shown in tree-dominated site A2100 (Figure $11 \mathrm{c}, 11 \mathrm{f})$. In these instances, it would be next to impossible to delineate these crowns even manually with expert knowledge due to the continuous nature of the crown coverage. In the field, coppiced stems often led to observed entanglement between crowns, where multiple stems would grow apart and fill in the canopy between neighboring crowns growing in a similar manner. In these cases, it is impossible to distinguish which crown belongs to which stem location recorded in the field from aerial imagery alone.

To avoid trying to choose a single metric of interest, indices should be explored using these metrics and parameterized based on a specific research question to encapsulate all metrics accordingly. For instance, if trying to determine the best data suited for polewood availability, MAE or tree heights and counts may be given greater weights than crown area as typically trees larger than three meters in height are sought for this use (Neke, Owen-Smith, N. and Witkowski 2006). Conversely, fuelwood availability may also rely on accurate crown metrics, which in turn would favor the use crown area (Ramírez-Mejía, Gómez-Tagle, and Ghilardi 2018), in which case the crown area MAE would be assigned a greater weight. Ecologists may be interested in quantifying habitat suitability which varies greatly dependent upon species of interest. Special needs would then inform the index model and utilized accordingly for ecological applications (Anderson and Gaston 2013). In this manner the utility of various methods and discrete spectral bands can be leveraged to answer particular questions of interest. 
Further, the method described in Figure 6 used to identify the modeled representative for in situ measured crowns could be modified to account for instances of over-segmented crowns, which could enrich the results depending on the task. An example would be to identify the delineated sub-polygon within the measured crown with the height of greatest magnitude if interested in identifying maximum tree heights. Since stems are known to be irregular, the stem location on the ground is rarely indicative of the location of observed crown maxima. The method could be similarly adjusted for estimating crown area as well. Through selection of the largest delineated sub-polygon that lies within or intersects the crown of interest, a polygon that better represents crown dimensions would be identified than by simply identifying the sub-polygon where the stem location was recorded in instances of multiple maxima detection.

\section{Limitations and Future Directions of Research}

The exploratory approach taken in this thesis, while informative, leads to questions regarding methods, data collected, and application of multispectral UAS data. Beginning with the absence of an intense ground control survey - methods for conducting and incorporating ground control are well documented and utilized (Padró et. al 2019; AgüeraVega, Carvajal-Ramírez, and Martínez-Carricondo 2017). For this study, it is possible that if applied properly, ground control points (GCP) could have resolved any possible intrinsic sensor differences with regards to results. Point matching in homogenous portions of the site could possibly be improved and any possible sensor differences normalized through the use of an independent survey instrument at multiple locations within the site. 
While the use of survey grade GCP could have improved results of this study, the larger aim is not dependent upon revisit of any of the particular study sites flown. With the goal of providing a quick, objective alternative to traditional reference sample collection, a time-expensive ground control protocol would be counterproductive and hinder the ability to collect necessary information efficiently. For future work the use of minimal GCPs should be considered, particularly for instances where GNSS malfunction could have major processing implications. Problems associated with accuracy of GNSS information as part of the ground control survey would come to bear, however, as differential correction methods are limited in this study area due to the absence of a reliable base station.

Also omitted from data processing in this study was proper radiometric calibration. Although a target was used to capture images with known reflectance values in the field, an error arose with "oversaturation" in the green band which prohibited a full radiometric calibration on the data collected. As is the case, results are limited to within flight relativity and reflectance between flights/sources cannot be directly compared without the use of a ratio-based calculation. Any use of these data for scaling to other products with greater extents or direct comparisons with other flights must rely on these ratio-based indices alone, unless an irradiance normalization procedure is used as tested in Tu et al. (2018). In this study, irradiance information is extracted from image EXIF data to adjust digital numbers based on the image with the lowest irradiance coefficient. Since these data are available, a novel method such as this one should be explored as a possible alternative to mainstream techniques.

This research has benefited greatly from support and ease of SfM-MVS implementation through the Pix4D environment, particularly for learning to handle, process, 
and interpret data using a SfM-MVS approach. Though a very powerful and approachable toolset, it is likely that outputs with the current software implementation cannot be considered as final products without further processing. In a comprehensive review of UAS applications to date, Singh and Frazier (2018) highlight many shortcomings of recent and past studies. Of these, the bidirectional reflectance effect is cited as rarely considered, yet agreed to be of greater influence as resolution increases (Marceau, Howarth, and Gratton 1994; Lelong et al. 2008; Tu et al. 2018). Unfortunately, this study has also overlooked bidirectional reflectance correction and it is unclear whether Pix4D image calibration goes beyond correcting intrinsic camera vignetting effects to take bidirectional reflectance into consideration. Tu et al. (2018) operationalize the Walthall method (Walthall et al. 1985) and while they found that the correction helped reduce variability among reflectance measurements, particularly in avocado trees with smaller foliage, mixed results suggest further research and examination is necessary. The mention of such a correction in the context of leaf size leads to the question of determining the appropriate GSD for quantifying crown dimensions, especially with the known problems associated with decreasing resolution and bidirectional reflectance.

Beyond the limitations of the processing methods used, individual parameter values chosen could also have an undesired effect on results of this work. In particular, this study incorporated Delaunay triangulation interpolation when constructing the DSM with the rationale that this method possibly allows for the estimation of understory characteristics. In reality, this decision may be prohibiting best delineation efforts with a "pitting" effect observed in single crowns resulting in the termination of region growing with the dalponte2016 implementation. This effect could be addressed through the use of a smoothing 
filter or by incorporation of a smoother interpolation method such as inverse distance weighting.

Although the aim was to collect data close to solar noon to reduce various illumination effects, the larger goal of flying as many sites as possible during a short field season would not allow for all imagery to be collected in identical solar conditions. Moving forward with these data, efforts should be focused on trying to normalize these outputs as flights strictly at solar noon were logistically impossible in the timeframe at hand.

Lastly, the field sampling protocol designed for collection of vegetation measurements within study sites was guided loosely by the Gibbes et al. (2010) implementation of the Walker (1976) transect protocol. With the goal of random collection of vegetation samples in mind, this method seems to have captured the variability well within and between sites. Where the sampling scheme fell short, however, is in the small sample sizes. As a result, site could not be used as a factor of analysis in due to low $n$ values and an intensive sampling scheme within a single site of each type could possibly have yielded a more robust dataset. Following an ecological sampling approach, sample sizes could be increased by incorporating measurements all of woody individuals with stems of a given diameter at breast height within a given distance as well as all seedlings and saplings within a micro-subplot (Popescu, Wynne, and Nelson 2002). While these more traditional forestry methods would increase sample sizes within plots, measures of heterogeneity that typifies savannas may be lost, as these methods are designed for homogenous plots for forest inventory. 


\section{CONCLUSIONS}

This study shows the potential for leveraging NIR data for quantifying vegetation structure in highly heterogeneous environments such as the semi-arid savannas of Southern Africa. Despite the relatively coarse GSD associated with the data collected by the Parrot Sequoia, results indicate that data into the NIR portion of the EM spectrum estimate vegetation structure as well or better than data with greater spatial detail collected across the visible portion of the spectrum. Also shown through this work is the utility of small off-theshelf systems for collection of valuable data attainable in a cost- and time-effective manner. Micro-UAS are increasing in the ease of application and should be considered by land managers globally as a potential method of data collection. What is more, we demonstrate that objective estimates of vegetation coverage can be derived from imagery collected with micro-UAS and hold great potential for informing analyses at other scales.

Study area and objectives require careful consideration before development of any UAS survey. In the context of semi-arid savannas, familiarity with the study area and/or ground observations can help guide decision making for input data used and methods employed. This study shows that region-growing techniques are strongest for individual crown delineation in all sites flown and also provide better estimates of fractional coverage in grass-dominated study sites where trees and shrubs are easily distinguishable. Height thresholding techniques provide stronger estimates of fractional coverage in more complex study sites where woody vegetation is continuous and in various stages of succession. These estimates may be most important, as degradation in terms of bush encroachment can have great implications for understanding impacts of disturbance in the context of varying land management strategies. 
In highly complex environments dealing with a myriad of uncertainties surrounding resource availability, climate, and usufruct rights, the importance of a strong understanding of the current and future states of land cover and function are of great interest. In KAZA, vegetation structure across the five member nations could manifest differently with respect to direction and magnitude as policy, management, and social systems vary between member countries. Establishing ways to balance conservation and livelihoods could hinge on a strong understanding of the landscape in terms of resource use and habitat suitability. This application of micro-UAS could very well be extended to stakeholder collaboration efforts (Cummings et al. 2017), where communities, land managers, and scientists can collect data to contribute to a larger effort of understanding the trajectory of land cover change and function. 


\section{REFERENCES}

Adelabu, S., O. Mutanga and E. Adam. 2014. Evaluating the impact of red-edge band from Rapideye image for classifying insect defoliation levels. ISPRS Journal of Photogrammetry and Remote Sensing 95, 34-41.

Agüera-Vega, F., F. Carvajal-Ramírez, and P. Martínez-Carricondo. 2017. Assessment of Photogrammetric Mapping Accuracy Based on Variation Ground Control Points Number Using Unmanned Aerial Vehicle. Measurement 98: 221-227.

Akpo, L.E. 1997. Phenological interactions between tree and understory herbaceous vegetation of a sahelian semi-arid savanna. Plant Ecology 131: 241-248.

Alonzo, M., H.-E. Andersen, D. Morton and B. Cook. 2018. Quantifying Boreal Forest Structure and Composition Using UAV Structure from Motion. Forests 9.

Anger, C. D., S. Mah, and S. K. Babey. 1994. Technological enhancements to the Compact Airborne Spectrographic Imager (CASI). In Proceedings of the 1st International Airborne Remote Sensing Conference and Exhibition, 11-15 September, Strasbourg, France (Ann Arbor, MI: ERIM International), pp. 205-213.

Anderson, K., and K. J. Gaston. 2013. Lightweight Unmanned Aerial Vehicles Will Revolutionize Spatial Ecology. Frontiers in Ecology and the Environment 11 (3): 138-146.

Avery, T.E., Burkhartn, H.E. 2001. Forest Measurements, 5th edn. McGraw-Hill, Boston.

Bond, W. J. \& G. F. Midgley. 2012. Carbon dioxide and the uneasy interactions of trees and savannah grasses. Philosophical Transactions of the Royal Society B 367: 601-12.

Bonnet, S. J. Lisein, and P. Lejeune. 2017. Comparison of UAS photogrammetric products for tree detection and characterization of coniferous stands detection and characterization of coniferous stands. International Journal of Remote Sensing 38: 5310-5337.

Botswana. 2011. Botswana population and housing census. Gaborone: Government Printers.

Brown, J. H., T. J. Valone, and C. G. Curtin. 1997. Reorganization of an arid system in response to recent climate change. Proceedings of the National Academy of Science 94: 9729-9733. 
Carleer, A.P., O. Debeir, and E. Wolff. 2005. Assessment of very high resolution satellite image segmentations. Photogrammetric Engineering \& Remote Sensing 71(11): 1285-1294.

Chen, Y., B. Stark, M. Kelly and S. D. Hogan. 2017. Unmanned aerial systems for agriculture and natural resources. California Agriculture 71: 5-14.

Chen, Q., D. Baldocchi, P. Gong, and M. Kelly. 2006. Isolating Individual Trees in a Savanna Woodland Using Small Footprint Lidar Data. Photogrammetric Engineering and Remote Sensing 72(8): 923-932.

Colomina, I. and P. Molina. 2014. Unmanned aerial systems for photogrammetry and remote sensing: A review. ISPRS Journal of Photogrammetry and Remote Sensing 92: 7997.

Coomes, D. A., M. Dalponte, T. Jucker, G. P. Asner, L. F. Banin, D. F. R. P. Burslem, S. L. Lewis, R. Nilus, O. L. Phillips, M. H. Phua, and L. Qie. 2017. Area-based vs. treecentric approaches to mapping forest carbon in Southeast Asian forests from airborne laser scanning data. Remote Sensing of Environment 194: 77-88.

Cummings, A. R., Y. Karale, G. R. Cummings, E. Hamer, P. Moses, Z. Norman, and V. Captain. 2017. UAV-derived data for mapping change on a swidden agriculture plot: preliminary results from a pilot study. International Journal of Remote Sensing 38: 2066-2082.

Cunliffe, A. M., R. E. Brazier and K. Anderson. 2016. Ultra-fine grain landscape-scale quantification of dryland vegetation structure with drone-acquired structure-frommotion photogrammetry. Remote Sensing of Environment 183: 129-143.

Curran, P. 1980. Multispectral remote sensing of vegetation amount. Progress in Physical Geography: Earth and Environment 4(3): 315 - 341

Dandois, J. P. and E. C. Ellis. 2010. Remote Sensing of Vegetation Structure Using Computer Vision. Remote Sensing 2: 1157-1176.

Dandois, J. P., M. Olano, and E. C. Ellis. 2015. Optimal Altitude, Overlap, and Weather Conditions for Computer Vision UAV Estimates of Forest Structure. Remote Sensing 7(10): 13895 - 13950.

DeFries, R., A. Hansen, B. L. Turner, R. Reid, and J. Liu. 2007. Land use change around protected areas: Management to balance human needs and ecological function. Ecological Applications 17(4): 1031-1038.

DJI. 2018. DJI Mavic Pro wherever you go. Available at https://www.dji.com/mavic (last accessed March 2018). 
d'Oleire-Oltmanns S., I. Marzolff I, K.D. Peter, and J.B. Ries. 2012. Unmanned aerial vehicle (UAV) for monitoring soil erosion in Morocco. Remote Sensing 4: 33903416 .

Eisenbeiß, Henri. UAV photogrammetry. Diss. ETH Zurich, 2009.

Eldridge, D.J., M.A. Bowker, F.T. Maestre, E. Roger, J.F. Reynolds, and W.G. Whitford. 2011. Impacts of shrub encroachment on ecosystem structure and functioning: Towards a global synthesis. Ecology Letters 14: 709-722.

Feng, X., G. Liu, J. M. Chen, M. Chen, J. Liu, W. M. Ju, R. Sun and W. Zhou. 2007. Net primary productivity of China's terrestrial ecosystems from a process model driven by remote sensing. Journal of Environmental Management 85: 563-573.

Filella I. and J. Penuelas. 1994. The red edge position and shape as indicators of plant chlorophyll content, biomass, and hydric status. International Journal of Remote Sensing 15(7): 1459-1470.

Fischer, J. T., B. F. N. Erasmus, E. T. F. Witkowski, J. van Aardt, K. J. Wessels, and G. P. Asner. 2014. Savanna woody vegetation classification- now in 3-D. Applied Vegetation Science 17: 172-184.

Foody, G. M. 1992. On the compensation for chance agreement in image classification accuracy assessment. Photogrammetric Engineering and Remote Sensing 58: 14591460.

Foody, G. M. 2015. An Assessment of Citizen Contributed Ground Reference Data for Land Cover Map Accuracy Assessment. ISPRS Annals of Photogrammetry, Remote Sensing and Spatial Information Sciences II-3/W5 (3): 219-225

Fraser, B.T. and R.G. Congalton. 2018. Issues in Unmanned Aerial Systems (UAS) Data Collection of Complex Forest Environments. Remote Sensing 10: 908.

Gaughan, A. E., F. R. Stevens, C. Gibbes, J. Southworth and M. W. Binford. 2012 Linking vegetation response to seasonal precipitation in the Okavango-Kwando-Zambezi catchment of southern Africa. International Journal of Remote Sensing 33: 67836804.

Georgopoulos, A., C. Oikonomou, E. Adamopoulos, and E.K. Stathopoulou. 2016. Evaluating unmanned aerial platforms for cultural heritage large scale mapping. The International Archives of the Photogrammetry, Remote Sensing and Spatial Information Sciences 41(5): 355-362.

Gibbes, C., S. Adhikari, L. Rostant, J. Southworth, and Y. Qiu. 2010. Application of Object Based Classification and High Resolution Satellite Imagery for Savanna Ecosystem Analysis. Remote Sensing 2(12): 2748-2772. 
Gibbes, C., J. Southworth, P. Waylen and B. Child. 2014. Climate variability as a dominant driver of post-disturbance savanna dynamics. Applied Geography 53: 389-401.

Gougeon, F. A. and T. Moore. 1988 Individual tree classification using MEIS-II imagery. Proceedings of 1988 International Geoscience and Remote Sensing Symposium: 1316 September, Edinburgh, Scotland, p. 927.

Gougeon, F. A. 1995. A crown-following approach to the automatic delineation of individual tree crowns in high spatial resolution aerial images. Canadian Journal of Remote Sensing 21: 274-284

Herrero, H., J. Southworth and E. Bunting. 2016. Utilizing Multiple Lines of Evidence to Determine Landscape Degradation within Protected Area Landscapes: A Case Study of Chobe National Park, Botswana from 1982 to 2011. Remote Sensing 8

Herrmann, S. M. and G. G. Tappan. 2013. Vegetation impoverishment despite greening: A case study from central Senegal. Journal of Arid Environments 90: 55-66.

Hollerman, M. and G. Morgenthal. 2013. Unmanned aerial vehicles (UAV) for the assessment of existing structures. Development, Design and Implementation 8: 1-8.

Jakubowski, M., W. Li, Q. Guo and M. Kelly. 2013. Delineating Individual Trees from Lidar Data: A Comparison of Vector- and Raster-based Segmentation Approaches. Remote Sensing 5: 4163-4186.

Jensen, J. R. 2016. Introductory digital image processing: a remote sensing perspective. Glenview, IL: Pearson Education, Inc.

Jensen, J. \& A. Mathews. 2016. Assessment of Image-Based Point Cloud Products to Generate a Bare Earth Surface and Estimate Canopy Heights in a Woodland Ecosystem. Remote Sensing 8(50) 1-13.

Jin, X. 2012. Segmentation-based image processing system. U.S. Patent 8,260,048, filed November 14, 2007, and issued Sept. 4, 2012.

Ke, Y. and L. J. Quackenbush. 2011. A review of methods for automatic individual treecrown delineation from passive remote sensing. International Journal of Remote Sensing 32(17): 4725-4747.

Kross, A., H. McNairn, D. Lapen, M. Sunohara and C. Champagne. 2015. Assessment of RapidEye vegetation indices for estimation of leaf area index and biomass in corn and soybean crops. International Journal of Applied Earth Observation and Geoinformation 34: 235-248. 
Lambin, E. F. 1999. Monitoring forest degradation in tropical regions by remote sensing: some methodological issues. Global Ecology and Biogeography 8: 191-198.

Lelong, C. C. D., P. Burger, G. Jubelin, B. Roux, S. Labbe, and F. Baret. 2008. Assessment of Unmanned Aerial Vehicles Imagery for Quantitative Monitoring of Wheat Crop in Small Plots. Sensors 8 (5): 3557-3585.

Lindberg, E. and J. Holmgren. 2017. Individual Tree Crown Methods for 3D Data from Remote Sensing. Current Forestry Reports 3: 19-31.

Marceau, D. J., P. J. Howarth, and D. J. Gratton.1994. Remote sensing and the measurement of geographical entities in a forested environment. 1. The scale and spatial aggregation problem. Remote Sensing of the Environment 49: 93-104.

Marx, A., D. McFarlane, and A. Alzahrani. 2017. UAV data for multi-temporal Landsat analysis of historic reforestation: a case study in Costa Rica. International Journal of Remote Sensing: 1-18.

Mathews, A. and J. Jensen. 2013. Visualizing and quantifying vineyard canopy LAI using an Unmanned Aerial Vehicle(UAV) collected high density structure from motion point cloud. Remote Sensing 5(5): 2164-2183.

Mayr, M. J., S. Malß, E. Ofner and C. Samimi. 2017. Disturbance feedbacks on the height of woody vegetation in a savannah: a multi-plot assessment using an unmanned aerial vehicle (UAV). International Journal of Remote Sensing 1-25.

McDowall, P., and H.J. Lynch. 2017. Ultra-fine Scale Spatially-Integrated Mapping of Habitat and Occupancy Using Structure-From-Motion. PLOS ONE 12(1): 1-16.

Neke, K. S., N. Owen-Smith, N. and E. T. F. Witkowski. 2006. Comparative resprouting response of Savanna woody plant species following harvesting: the value of persistence. Forest Ecology and Management 232: 114-123.

Nellemann, C., S. R. Moe, and L.P Rutina. 2002. Links between terrain characteristics and forage patterns of elephants (Loxodonta Africana) in Northern Botswana. Journal of Tropical Ecology 18: 835-844.

Nunes, M. H., R. M. Ewers, E. C. Turner, and D. A. Coomes. 2017. Mapping aboveground carbon in oil palm plantations using LiDAR: A comparison of tree-centric versus area-based approaches. Remote Sensing 9(8): 816.

Olson, J.M., G. Alagarswamy, J. A. Andresen, D. J. Campbell, A. Y. Davis, J. Ge, M. Huebner, B. M. Lofgren, D. P. Lusch, N. J. Moore, B. C. Pijanowski, J. Qi, P. K. Thornton, N. M. Torbick, and J. Wang. 2008. Integrating diverse methods to understand climate-land interactions in East Africa. Geoforum 39, 898-911. 
Padró, J.-C., F.-J. Muñoz, J. Planas and X. Pons. 2019. Comparison of four UAV georeferencing methods for environmental monitoring purposes focusing on the combined use with airborne and satellite remote sensing platforms. International Journal of Applied Earth Observation and Geoinformation 75: 130-140.

Pix4Dmapper 3.3 USER MANUAL. Pix4D SA: Lausanne, Switzerland, 2017.

Pontius, R. G. and M. Millones. 2011. Death to Kappa: birth of quantity disagreement and allocation disagreement for accuracy assessment. International Journal of Remote Sensing 32: 4407-4429.

Popescu, S.C., and R.H. Wynne. 2004. Seeing the trees in the forest: Using lidar and multispectral data fusion with local filtering and variable window size for estimating tree height. Photogrammetric Engineering \& Remote Sensing 70:589-604.

Pricope, N., A. Gaughan, J. All, M. Binford and L. Rutina. 2015. Spatio-Temporal Analysis of Vegetation Dynamics in Relation to Shifting Inundation and Fire Regimes: Disentangling Environmental Variability from Land Management Decisions in a Southern African Transboundary Watershed. Land 4: 627-655.

Ramírez-Mejía, D., A. Gómez-Tagle, and A. Ghilardi. 2018. Using aerial photography to estimate wood suitable for charcoal in managed oak forests. Environmental Research Letters 13.

Randolph, J. C., G. M. Green, J. Belmont, T. Burscu, and D. Welch. 2005. Forest Ecosystems and the Human Dimensions. In Seeing the Forest and the Trees: Human Environment Interactions in Forest Ecosystems, ed. Moran, E. F. and E. Ostrom, 105-125. Cambridge, MA: MIT Press.

Roques, K.G., T. G. O’Connor, and A. R. Watkinson. 2001. Dynamics of shrub encroachment in an African savanna: Relative influences of fire, herbivory, rainfall, and density dependence. Journal of Applied Ecology 38: 268-280.

Van Langevelde, F., C. van de Vijver, L. Kumar, J. van de Koppel, N. de Ridder, J. van Andel, A. K. Skidmore, J. Hearne, L. Stroosnijder, W. J. Bond, et al. 2002. Effects of fire and herbivory on the stability of savanna ecosystems. Ecology 84: 337-350.

Salamí, E., C. Barrado and E. Pastor. 2014. UAV Flight Experiments Applied to the Remote Sensing of Vegetated Areas. Remote Sensing 6: 11051-11081.

Scholes, R.J. and S.R. Archer. 1997. Tree-grass interactions in savanna. Annual Review of Ecology and Systematics 28: 517-544. 
Smith, M.W., J. L Carrivick, and D. J. Quincey. 2015. Structure from motion photogrammetry in physical geography. Progress in Physical Geography 40 (2): 247 -275 .

Stevens, N., B. F. Erasmus, S. Archibald \& W. J. Bond. 2016. Woody encroachment over 70 years in South African savannahs: overgrazing, global change or extinction aftershock? Philosophical Tranactions B 371.

Stone M. T. 2015. Community Empowerment Through Community-Based Tourism: The Case of Chobe Enclave Conservation Trust in Botswana. In: van der Duim R., Lamers M., van Wijk J. (eds) Institutional Arrangements for Conservation, Development and Tourism in Eastern and Southern Africa. Springer, Dordrecht

Tonkin T.N., N.G. Midgley, D.J. Graham, and J.C. Labadz. 2014. The potential of small unmanned aircraft systems and structure-from-motion for topographic surveys: A test of emerging integrated approaches at Cwm Idwal, North Wales. Geomorphology 226: $35-43$.

Torresan, C., A. Berton, F. Carotenuto, S.F. DiGennaro, B. Gioli, A. Matese, F. Miglietta, C. Vagnoli, A. Zaldei, and L. Wallace. 2017. Forestry applications of UAVs in Europe: a review. International Journal of Remote Sensing 38: 2427-2447.

Tu, Y. H., S. Phinn, K. Johansen, and A. Robson. 2018. Assessing Radiometric Correction Approaches for Multi-Spectral UAS Imagery for Horticultural Applications. Remote Sensing 10: 1684.

Tucker, C. J. 1979. Red and photographic infrared linear combinations for monitoring vegetation. Remote Sensing of the Environment 8:127-150.

Turk, G. 2002. Map evaluation and “chance correction”. Photogrammetric Engineering and Remote Sensing 68: 123-133.

Turner, D., A. Lucieer and L. Wallace. 2014. Direct Georeferencing of Ultrahigh-Resolution UAV Imagery. IEEE Transactions on Geoscience and Remote Sensing 52: 27382745.

Van Auken, O. W. 2009. Causes and consequences of woody plant encroachment into western North American grasslands. Journal of Environmental Management 90: $2931-2942$.

Verburg, P.H., P. Schot, M. Dijst, A. Veldkamp. 2004. Land use change modelling: current practice and research priorities. GeoJournal 61: 309-324

Verburg, P. H., J. van de Steeg, A. Veldkamp and L. Willemen. 2009. From land cover change to land function dynamics: a major challenge to improve land characterization. Journal of Environmental Management 90: 1327-35. 
Walker, B. H. 1976. An approach to the monitoring of changes in the composition and utilization of woodland and savanna vegetation. Southern African Journal of Wildlife Research 6: 1-32.

Wallace, L., A. Lucieer, Z. Malenovsky, D. Turner, and P. Vopenka. 2016. Assessment of Forest Structure Using Two UAV Techniques: A comparison of Airborne Laser Scanning and Structure from Motion (SfM) Point clouds. Forestry 7(62): 1-16.

Walthall, C.L.; Norman, J.M.; Welles, J.M.; Campbell, G.; Blad, B.L. 1985. Simple equation to approximate the bidirectional reflectance from vegetative canopies and bare soil surfaces. Applied Optics 24: 383-387.

Ward, D. 2005. Do we understand the causes of bush encroachment in African savannas? African Journal of Range and Forage Science 22(2): 101-105.

Warrens, M. J. 2015. Properties of the quantity disagreement and the allocation disagreement. International Journal of Remote Sensing 36(5): 1439-1446.

Zahawi, R. A., J. P. Dandois, K. D. Holl, D. Nadwodny, J. L. Reid and E. C. Ellis. 2015. Using lightweight unmanned aerial vehicles to monitor tropical forest recovery. Biological Conservation 186: 287-295.

Zhang, Y.J. 1997. Evaluation and comparison of different segmentation algorithms. Pattern Recognition Letters 18: 963-974.

Zhang, X., M. A. Friedl, C. B. Schaaf, A. H. Strahler, J. C. F. Hodges, F. Gao, B. C. Reed and A. Huete. 2003. Monitoring vegetation phenology using MODIS. Remote Sensing of Environment 84: 471-475.

Zhen, Z., L. Quackenbush and L. Zhang. 2016. Trends in Automatic Individual Tree Crown Detection and Delineation-Evolution of LiDAR Data. Remote Sensing 8. 


\begin{abstract}
APPENDIX
Code used for processing data can be found in the following locations:

https://figshare.com/account/home\#/projects/61694

https://github.com/neko1010/multi_plot_assessment

In these collections Windows batch files can be found used for processing UAS image projects identically. Also, Python tools were developed that access ArcGIS functions through the arcpy package instead of through the graphical user interface. These tools ensure that all processes were executed identically and outputs stored similarly. R code found in the repository was largely used to apply LiDAR analyses to the SfM-MVS point clouds generated via Pix4D. Other scripts found (either Python or R) are used for a variety of applications including plot generations, statistical calculations, and other assessment metrics.
\end{abstract}




\section{CURRICULUM VITAE}

\section{Nicholas E. Kolarik}

nicholaskolarik@gmail.com

\section{$\underline{\text { RESEARCH INTERESTS }}$}

Human-environment interactions, land systems science, remote sensing, hydro-climatology, geospatial analysis, Free and Open Source Software programming.

\section{$\underline{\text { EDUCATION }}$}

University of Louisville - Louisville, KY

M.S in Applied Geography

Thesis: A multi-plot assessment of vegetation structure using a micro unmanned aerial system (UAS) in a semi-arid savanna environment

2017 University of Louisville - Louisville, KY

B.S. in Geography, concentration in environmental analysis

\section{$\underline{\text { AWARDS }}$}

Graduate Dean's Citation 2019

Outstanding Graduate Student, Department of Geography and Geosciences 2019 (\$500)

Travel grants: Graduate Student Council, Geography Department 2018 (\$800)

College of Arts \& Sciences Dean's Office Graduate Assistantship 2017-2019 (\$24,000 + tuition)

Lou Seig Award in Geography 2017 (\$500) 


\section{$\underline{\text { REFEREED PUBLICATIONS }}$}

\section{$\underline{\text { In Review }}$}

Kolarik, N. E., M.G. Ellis, A.E. Gaughan, and F.R. Stevens. Seasonal Differences in Tree Crown Delineation Using Multispectral UAS Data and Structure from Motion. Submitted to Remote Sensing Letters.

\section{Published}

Boldt, J.A., J. G. Lant, and N. E. Kolarik. 2018. Flood-inundation study of the North Fork Kentucky River at Hazard, Kentucky: U.S. Geological Survey scientific investigation report. https://doi.org/10.3133/sir20185122

\section{PRESENTATIONS and POSTERS}

Kolarik, N. E._A multi-plot assessment of vegetation structure using a micro-unmanned aerial system (UAS) in a semi-arid environment. Presented at the American Association of Geographers Annual Meeting, Washington, D.C. April 4, 2019.

Kolarik, N. E., A.E. Gaughan, and F.R. Stevens. Crown delineation using multispectral point cloud data. Presented at the American Association of Geographers Annual Meeting, New Orleans, LA. April 13, 2018. DOI: 10.13140/RG.2.2.25621.63209

Kolarik, N. E. Crown delineation using multispectral point cloud data. Presented at the Graduate Student Regional Research Conference, University of Louisville. March 2, 2018.

\section{$\underline{\text { RELATED EXPERIENCE }}$}

2017 - Present $\quad$ Research assistant, KAZAVA Project (https://kazava.weebly.com/)

- Field work in Botswana and Zambia- collection of UAS data, in situ validation measurements, and reference samples

- Presentation of research at University of Namibia

- UAS data processing using a structure from motion approach

2017 - $2018 \quad$ Research assistant, OKI USGS Water Science Center Specialized Water Modeling and Applied Technology group - student contract

- Geospatial analysis

- Development of python tools

2016 - $2017 \quad$ Physical science technician, OKI USGS Water Science Center Sediment Lab - student contract

2016 Undergraduate Teaching assistant, GIS and Water Resources 


\section{PROFESSIONAL MEMBERSHIP}

American Association of Geographers (AAG)

American Association of the Advancement in Science (AAAS) 